\title{
Circulating MicroRNAs in Young Patients with Acute Coronary Syndrome
}

\author{
Kind-Leng Tong ${ }^{1}$ (D), Ahmad Syadi Mahmood Zuhdi ${ }^{2}$ (D), Wan Azman Wan Ahmad ${ }^{2}$, \\ Paul M. Vanhoutte ${ }^{3}$, Joao Pedro de Magalhaes ${ }^{4}$, Mohd Rais Mustafa ${ }^{1}$ and Pooi-Fong Wong ${ }^{1, *}$ \\ 1 Department of Pharmacology, Faculty of Medicine, University of Malaya, 50603 Kuala Lumpur, Malaysia; \\ tkindleng@gmail.com (K.-L.T.); rais@um.edu.my (M.R.M.) \\ 2 Department of Medicine, Faculty of Medicine, University of Malaya, 50603 Kuala Lumpur, Malaysia; \\ syadizuhdi@yahoo.co.uk (A.S.M.Z.); wanazman@ummc.edu.my (W.A.W.A.) \\ 3 State Key Laboratory of Pharmaceutical Biotechnology, Department of Pharmacology and Pharmacy, \\ Li Ka Shing Faculty of Medicine, The University of Hong Kong, Hong Kong, China; vanhoutt@hku.hk \\ 4 Integrative Genomics of Ageing Group, Institute of Ageing and Chronic Disease, University of Liverpool, \\ Liverpool L7 8TX, UK; jp@senescence.info \\ * Correspondence: wongpf@um.edu.my; Tel.: +603-7967-7022 (ext. 2065); Fax: +603-7967-4791
}

Received: 6 April 2018; Accepted: 8 May 2018; Published: 15 May 2018

\begin{abstract}
Circulating microRNAs (miRNAs) hold great potential as novel diagnostic markers for acute coronary syndrome (ACS). This study sought to identify plasma miRNAs that are differentially expressed in young ACS patients (mean age of $38.5 \pm 4.3$ years) and evaluate their diagnostic potentials. Small RNA sequencing (sRNA-seq) was used to profile plasma miRNAs. Discriminatory power of the miRNAs was determined using receiver operating characteristic (ROC) analysis. Thirteen up-regulated and 16 down-regulated miRNAs were identified in young ACS patients. Quantitative reverse transcription-polymerase chain reaction (qRT-PCR) validation showed miR-183-5p was significantly up-regulated (8-fold) in ACS patients with non-ST-segment elevated myocardial infarction (NSTEMI) whereas miR-134-5p, miR-15a-5p, and let-7i-5p were significantly down-regulated (5-fold, 7-fold and 3.5-fold, respectively) in patients with ST-segment elevated myocardial infarction (STEMI), compared to the healthy controls. MiR-183-5p had a high discriminatory power to differentiate NSTEMI patients from healthy controls (area under the curve $(A U C)$ of ROC $=0.917$ ). The discriminatory power for STEMI patients was highest with let-7i-5p $(A U C=0.833)$ followed by miR-134-5p and miR-15a-5p and this further improved (AUC $=0.935)$ with the three miRNAs combination. Plasma miR-183-5p, miR-134-5p, miR-15a-5p and let-7i-5p are deregulated in STEMI and NSTEMI and could be potentially used to discriminate the two ACS forms.
\end{abstract}

Keywords: circulating microRNAs; acute coronary syndrome; STEMI; NSTEMI

\section{Introduction}

Coronary artery disease (CAD) is a leading cause of death worldwide. Clinical presentations of CAD include silent ischemia, stable angina pectoris, unstable angina, myocardial infarction, heart failure, and sudden death [1]. Acute coronary syndrome (ACS) refers to any group of clinical symptoms compatible with acute myocardial ischemia and includes unstable angina pectoris, ST-segment elevated myocardial infarction (STEMI) and non-ST-segment elevated myocardial infarction (NSTEMI) [2]. Between the years 2011 and 2013, approximately 15,000 ACS cases were reported in Malaysia, with more than $75 \%$ afflicting patients older than 50 years of age. To date, the rates of myocardial infarction, readmission of patients with ACS and death remain high, underscoring the need for more aggressive health awareness, education, and non-pharmacological approaches to counter this rising prevalence of 
ACS as well as innovative early and reliable biomarkers to facilitate rapid and more accurate diagnosis and subsequent treatment.

Electrocardiography (ECG) and cardiac troponins are conventional tests used for the diagnosis of ACS. ECG detects transient ST-segment elevations, dynamic T-wave changes, and ST depressions during acute events [3]; however, ECG patterns that are diagnostic of ACS are not present in approximately half of the ACS patients at the time of presentation in an emergency department [4]. Hence a significant proportion of ACS may elude detection by ECG alone. For this reason, the diagnosis of ACS remains a challenge especially in individuals without clear symptoms or electrocardiographic features.

Cardiac troponin I or $\mathrm{T}$ are not detectable in the blood of healthy individuals and are more predictive of myocardial necrosis compared to creatine kinase-myocardial band isoenzyme (CK-MB) [5]. However, cardiac troponins may not be elevated consistently at the onset of myocardial infarction, which can hinder early diagnosis [6]. Moreover, changes in troponin levels also occur under conditions other than ACS (including chronic renal failure, cerebrovascular accidents, acute pulmonary embolism, hypertensive crisis, tachy- or bradyarrhythmias, acute inflammatory myocarditis, and skeletal myopathies) [7]. Misinterpretation of detectable troponin levels may lead to confusion of diagnosis and inappropriate choice of therapy. Hence, there is a need to identify additional biomarkers to support accurate clinical diagnosis and management.

MicroRNAs (miRNAs) have been identified and advocated as biomarkers for the diagnosis and /or prognosis of cardiovascular diseases such as ischemic heart disease, heart failure, stroke, and CAD [8,9]. They are short $(\approx 22$ nucleotides), non-coding RNAs that regulate genes post-transcriptionally by translational repression following partial complementary binding to target sites on untranslated regions of mRNAs [10-12]. MiRNAs play important roles in various biological and cellular processes by regulating the expression of their target genes in signaling pathways. They are present in tissues and in the circulation; aberrations of miRNAs expression levels occur in various diseases including cancer and cardiovascular disorders [13-16]. In the latter, for example, the expressions of miR-134, miR-198, and miR-370 are increased in patients with unstable angina pectoris and acute pulmonary embolism $[17,18]$. The use of circulating miRNAs for the diagnosis of diseases is reliable as they are stable in plasma or serum and their expressions can be easily quantified by quantitative reverse transcription-polymerase chain reaction (qRT-PCR). In this regard, it would be advantageous to detect early alterations in the levels of circulating miRNAs for the diagnosis of ACS during the early onset of symptoms. This is exemplified by the detection of circulating miRNAs within three hours of symptom onset and in patients with initially negative troponin levels [19]. Specifically, peak expression levels of miR-19b-5p, miR-134-5p, and miR-186-5p can be detected approximately ten hours after the onset of chest pain in patients with acute myocardial infarction [20]. Moreover, their presence also positively correlates with cardiac troponin I. Given that a single miRNA can have various targets and in view of the cooperative mechanisms involved, a multi panel approach of miRNAs detection could further increase diagnostic efficiency. Taken in conjunction, the available information suggests that circulating levels of certain miRNAs have strong potentials as biomarkers for the diagnosis of cardiovascular diseases.

In the diagnosis of ACS, the identification and evaluation of the use of circulating miRNAs have thus far focused on patients of higher age groups, as older people are more at risk for ACS where its prevalence is indeed higher in the elderly [20-22]. Apart from age, other risk factors for ACS include smoking, diabetes, hypertension, obesity, and hypercholesterolemia [23,24]. In Malaysia, approximately $23 \%$ of ACS cases involved individuals below 50 years of age and the majority of these patients were male $(\sim 80 \%)$ [25]. In addition, a retrospective review in the northern region of Malaysia further revealed that $55 \%$ of these patients had premature CAD [26]. The increasing prevalence of ACS in younger individuals could be linked to the continuous rise in obesity, diabetes, and hypertension in that age group in Malaysia. The occurrence of ACS in young individuals is uncommon and is often overlooked during clinical examination but the prognosis is more favorable compared to that of elderly 
patients $[27,28]$. Hence, there is a need to identify suitable early biomarkers for young ACS patients as they are often under-diagnosed due to a lower clinical suspicion. The present study sought to achieve this by performing small RNA sequencing to identify plasma miRNAs in young ACS patients.

\section{Results}

\subsection{Baseline Characteristics of the Study Population}

Assessment of clinical characteristics revealed no statistical difference between the healthy control subjects with the ACS subgroups for most of the clinical variables measured except for significantly higher plasma levels of high-density lipoproteins (HDL) and lower white blood cell counts (WBC) in the healthy controls compared to the ACS group (Tables 1 and 2). This is anticipated as lower plasma HDL level in patients is associated with the incidence of premature CAD [26,29]. There were also no significant differences in the age $(p=0.16)$ and CK-MB levels $(p=0.69)$ between the ACS and healthy subjects. As expected, patients with STEMI had higher troponin I and CK-MB levels compared to NSTEMI subjects because the degree of coronary occlusion is worse in STEMI (Tables 1 and 2). The percentage of patients prescribed with medications was also higher in the STEMI than in the NSTEMI group. This reflects that ACS with STEMI, which has a worse outcome, warrants more aggressive treatment.

Table 1. Clinical characteristics of acute coronary syndrome (ACS) patients and control subjects used for small-RNA sequencing.

\begin{tabular}{|c|c|c|c|c|}
\hline & $\begin{array}{l}\text { STEMI Patients } \\
\quad(n=11)\end{array}$ & $\begin{array}{l}\text { NSTEMI Patients } \\
\qquad(n=3)\end{array}$ & $\begin{array}{l}\text { Healthy Controls } \\
\qquad(n=14)\end{array}$ & $p$-Value \\
\hline Age (years) & $36.36 \pm 1.73$ & $39.67 \pm 2.96$ & $35.55 \pm 1.92$ & 0.5851 \\
\hline Male sex (\% male) & $11(100)$ & $3(100)$ & $14(100)$ & \\
\hline \multicolumn{5}{|l|}{ Health history, $n(\%)$ : } \\
\hline Alcohol drinker & $1(9.09)$ & $0(0)$ & $0(0)$ & \\
\hline Smokers & $11(100)$ & $1(33.33)$ & $0(0)$ & \\
\hline Morbid Obesity & $0(0)$ & $0(0)$ & $0(0)$ & \\
\hline Familial Hypercholesterolemia & $1(9.09)$ & $0(0)$ & $0(0)$ & \\
\hline Hypertension & $4(36.36)$ & $0(0)$ & $1(7.14)$ & \\
\hline Diabetes mellitus & $1(9.09)$ & $1(33.33)$ & $1(7.14)$ & \\
\hline Family History of CVD & $7(63.64)$ & $2(66.67)$ & $0(0)$ & \\
\hline \multicolumn{5}{|l|}{${ }^{\#}$ Medications, $n(\%)$ : } \\
\hline Acetylsalicylic acid & $9(81.82)$ & $2(66.67)$ & $0(0)$ & \\
\hline Lipid lowering drugs & $10(90.91)$ & $2(66.67)$ & $0(0)$ & \\
\hline Beta-blocker & $6(54.55)$ & $1(33.33)$ & $0(0)$ & \\
\hline Others & $2(18.18)$ & $1(33.33)$ & $0(0)$ & \\
\hline \multicolumn{5}{|l|}{ Laboratory tests } \\
\hline $\mathrm{WBC}\left(\times 10^{9} / \mathrm{L}\right)$ & $12.63 \pm 1.14$ & $11.90 \pm 1.79$ & $8.68 \pm 0.56$ & 0.0110 * \\
\hline Glucose (mmol/L) & $6.19 \pm 0.55$ & $8.10 \pm 2.61$ & $6.26 \pm 0.58$ & 0.4087 \\
\hline $\mathrm{TC}(\mathrm{mmol} / \mathrm{L})$ & $4.83 \pm 0.40$ & $5.07 \pm 0.45$ & $5.26 \pm 0.44$ & 0.7581 \\
\hline $\mathrm{HDL}(\mathrm{mmol} / \mathrm{L})$ & $0.96 \pm 0.07$ & $0.78 \pm 0.10$ & $1.19 \pm 0.09$ & 0.0329 * \\
\hline $\mathrm{LDL}(\mathrm{mmol} / \mathrm{L})$ & $3.14 \pm 0.37$ & $3.39 \pm 0.30$ & $3.33 \pm 0.38$ & 0.5610 \\
\hline $\mathrm{TG}(\mathrm{mmol} / \mathrm{L})$ & $1.61 \pm 0.22$ & $1.97 \pm 0.52$ & $1.65 \pm 0.20$ & 0.7493 \\
\hline Troponin I (ng/mL) & $11.78 \pm 4.89$ & $1.94 \pm 0.69$ & ND & ND \\
\hline Creatine kinase (U/L) & $1859.67 \pm 619.44$ & $496.00 \pm 337.93$ & $641.3 \pm 495.96$ & 0.1037 \\
\hline CK-MB $(\mu \mathrm{g} / \mathrm{L})$ & $88.33 \pm 25.69$ & $28.00 \pm 25.03$ & $4.03 \pm 2.07$ & 0.0698 \\
\hline
\end{tabular}


Table 2. Clinical characteristics of ACS patients and control subjects used for quantitative reverse transcription-polymerase chain reaction (qRT-PCR) validation.

\begin{tabular}{|c|c|c|c|c|}
\hline & $\begin{array}{l}\text { STEMI Patients } \\
\qquad(n=9)\end{array}$ & $\begin{array}{l}\text { NSTEMI Patients } \\
(n=5)\end{array}$ & $\begin{array}{l}\text { Healthy Controls } \\
\qquad(n=12)\end{array}$ & $p$-Value \\
\hline Age (years) & $37.78 \pm 1.29$ & $37.80 \pm 2.15$ & $36.80 \pm 1.83$ & 0.8912 \\
\hline Male sex (\% male) & $9(100)$ & $5(100)$ & $12(100)$ & \\
\hline $\begin{array}{l}\text { Health history, } n(\%) \text { : } \\
\text { Alcohol drinker } \\
\text { Smokers } \\
\text { Morbid Obesity } \\
\text { Familial Hypercholesterolemia } \\
\text { Hypertension } \\
\text { Diabetes mellitus } \\
\text { Family History of CVD }\end{array}$ & $\begin{array}{c}1(11.11) \\
8(88.89) \\
0(0) \\
0(0) \\
0(0) \\
0(0) \\
5(55.56)\end{array}$ & $\begin{array}{c}0(0) \\
2(40.00) \\
0(0) \\
0(0) \\
0(0) \\
2(40.00) \\
3(60.00)\end{array}$ & $\begin{array}{c}0(0) \\
0(0) \\
0(0) \\
0(0) \\
1(8.33) \\
1(8.33) \\
0(0)\end{array}$ & \\
\hline $\begin{array}{l}\text { \# Medications, } n(\%) \text { : } \\
\text { Acetylsalicylic acid } \\
\text { Lipid lowering drugs } \\
\text { Beta-blocker } \\
\text { Others }\end{array}$ & $\begin{array}{l}8(88.89) \\
8(88.89) \\
7(77.78) \\
1(11.11) \\
\end{array}$ & $\begin{array}{l}3(60.00) \\
3(60.00) \\
2(40.00) \\
1(20.00)\end{array}$ & $\begin{array}{l}0(0) \\
0(0) \\
0(0) \\
0(0)\end{array}$ & \\
\hline $\begin{array}{l}\text { Laboratory tests } \\
\text { WBC }\left(\times 10^{9} / \mathrm{L}\right) \\
\text { Glucose }(\mathrm{mmol} / \mathrm{L}) \\
\text { TC }(\mathrm{mmol} / \mathrm{L}) \\
\text { HDL }(\mathrm{mmol} / \mathrm{L}) \\
\text { LDL }(\mathrm{mmol} / \mathrm{L}) \\
\text { TG }(\mathrm{mmol} / \mathrm{L}) \\
\text { Troponin I }(\mathrm{ng} / \mathrm{mL}) \\
\text { Creatine kinase }(\mathrm{U} / \mathrm{L}) \\
\text { CK-MB }(\mu \mathrm{g} / \mathrm{L})\end{array}$ & $\begin{aligned} 13.22 & \pm 1.63 \\
6.33 & \pm 0.49 \\
5.66 & \pm 0.62 \\
1.14 & \pm 0.26 \\
3.55 & \pm 0.68 \\
2.04 & \pm 0.29 \\
6.29 & \pm 6.24 \\
1526.89 & \pm 461.82 \\
140.28 & \pm 83.35\end{aligned}$ & $\begin{aligned} 12.02 & \pm 1.17 \\
9.04 & \pm 2.00 \\
5.46 & \pm 0.41 \\
0.99 & \pm 0.12 \\
3.80 & \pm 0.37 \\
1.46 & \pm 0.16 \\
5.97 & \pm 4.23 \\
760.20 & \pm 452.37 \\
35.20 & \pm 17.47\end{aligned}$ & $\begin{aligned} 9.13 & \pm 0.74 \\
7.10 & \pm 0.71 \\
5.62 & \pm 0.49 \\
1.27 & \pm 0.09 \\
3.58 & \pm 0.46 \\
1.72 & \pm 0.27 \\
\mathrm{ND} & \\
910.50 & \pm 721.50 \\
5.55 & \pm 2.45\end{aligned}$ & $\begin{array}{l}0.0587 \\
0.1979 \\
0.9685 \\
0.0841 \\
0.7561 \\
0.9510 \\
\text { ND } \\
0.3601 \\
0.2262\end{array}$ \\
\hline
\end{tabular}

Abbreviations: CVD, cardiovascular disease; WBC, white blood cells; TC, total cholesterol; HDL, high-density lipoproteins; LDL, low-density lipoproteins; CK-MB, creatine kinase-myocardial band; ND, not determined; \# Medications were given on admission/in the ward.

\subsection{Detection of miRNA Expression in Plasma of Young ACS by Small RNA Sequencing (sRNA-seq)}

On the average, 58,000 reads mapped to the human genome were obtained per sample and after applying the filter, an average of 9086 clean reads were obtained (Figure 1A). Length distribution analysis showed that most reads were in the range of 18 to $24 \mathrm{nt}$ in plasma pools of both the ACS patients and the healthy controls, which is consistent with the common length of miRNAs [30,31]. MiRNAs were the major component of the small RNAs population in the dataset (Figure 1B). MiRDeep2 analysis identified a total of 1702 miRNAs, of which 752 are known, from the pooled samples. On the average, $38.5 \%$ of mapped nr-reads were aligned to annotated miRNA genes in the reference genome (Figure 1C). In the STEMI group, a total of 166 miRNAs with reads above 200 and present in more than five subjects were retained in the list used for differential expression analysis using DESeq2 (https://bioconductor.org/packages/release/bioc/html/DESeq2.html) [32]. A cut-off of 10\% false discovery rate (FDR) yielded 13 up-regulated and 16 down-regulated miRNAs in the STEMI group (Table 3). MiRNAs with more than 1.5-fold changes in expression (i.e., miR-183-5p, miR-15a-5p, miR-375, miR-1307-5p, miR-134-5p, and let-7i-5p) were selected for subsequent qRT-PCR validation. 
A

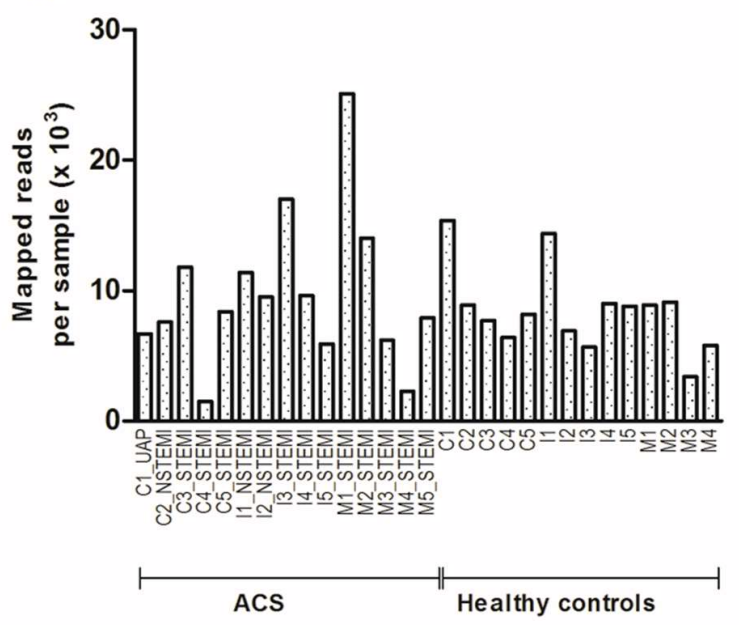

B

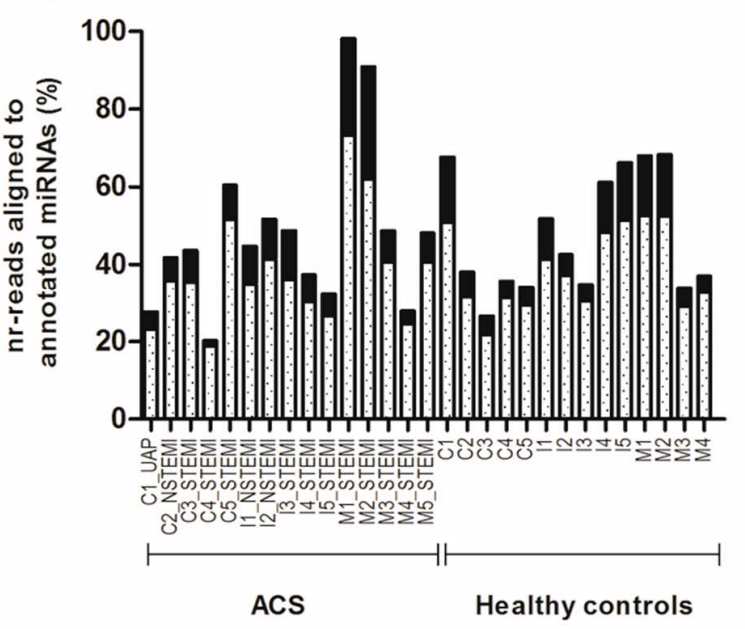

C

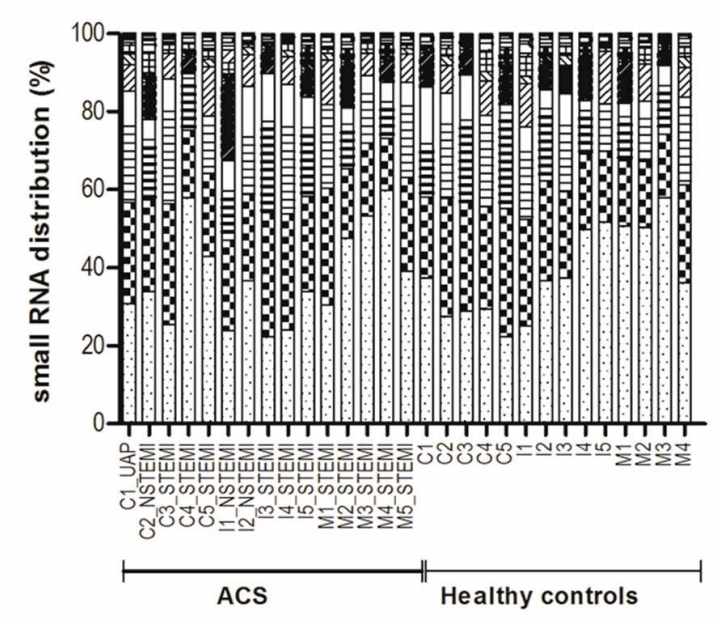

miRNA

EI INR

曰IGR

$\square$ misc_RNA

III] protein_coding

rRNA

曲 snoRNA

snRNA

$\Delta \nabla$ processed_transcript

[D pseudogene

m tRNA

lincRNA

ncRNA

$\mathbf{X X}$ antisense

athers

Figure 1. Overview of mapped reads, distribution of RNA species and miRNAs. (A) Number of reads $\left(\times 10^{3}\right)$ mapped to the human genome for all samples. These include all RNA species [small nucleolar (sno), small nuclear (sn), rRNA, tRNA, non-coding (nc), long coding (linc), intergenic (IGR), intronic (INR) and miscellaneous other (misc) RNA]. (B) Distribution of the mapped reads in the reference genome (GRCh37). (C) Percentages of mapped reads aligned to annotated miRNA genes in the reference genome for all samples. 
Table 3. Significantly deregulated miRNAs in ST-segment elevated myocardial infarction (STEMI) patients compared to healthy controls.

\begin{tabular}{|c|c|c|c|c|c|c|}
\hline miRNA & $\begin{array}{l}\text { Base } \\
\text { Mean }\end{array}$ & $\begin{array}{c}\log _{2} \text { Fold } \\
\text { Change }\end{array}$ & $\begin{array}{c}\text { Fold } \\
\text { Change }\end{array}$ & Regulation & $p$-Value & $\begin{array}{c}\text { Adjusted } \\
p \text {-Value }\end{array}$ \\
\hline hsa-miR-183-5p_MIMAT0000261 & 133.430 & 2.232 & 4.699 & Up & 0.0000856 & 0.00317 \\
\hline hsa-miR-19a-5p_MIMAT0004490 & 269.760 & 1.732 & 3.322 & Up & 0.00379 & 0.03740 \\
\hline hsa-miR-15a-5p_MIMAT0000068 & 466.668 & 1.680 & 3.205 & Up & 0.00252 & 0.02723 \\
\hline hsa-miR-101-5p_MIMAT0004513 & 1857.448 & 1.053 & 2.075 & Up & 0.00942 & 0.07019 \\
\hline hsa-miR-101-3p_MIMAT0000099 & 1857.448 & 1.053 & 2.075 & Up & 0.00942 & 0.07019 \\
\hline hsa-miR-103a-3p_MIMAT0000101 & 5231.824 & 1.047 & 2.066 & Up & 0.00250 & 0.02723 \\
\hline hsa-miR-107_MIMAT0000104 & 5231.824 & 1.047 & 2.066 & $\mathrm{Up}$ & 0.00250 & 0.02723 \\
\hline hsa-miR-103a-2-5p_MIMAT0009196 & 5231.824 & 1.047 & 2.066 & Up & 0.00250 & 0.02723 \\
\hline hsa-miR-16-5p_MIMAT0000069 & 5923.048 & 1.037 & 2.052 & Up & 0.01173 & 0.07091 \\
\hline hsa-miR-16-5p_MIMAT0000069 & 5925.776 & 1.036 & 2.051 & Up & 0.01180 & 0.07091 \\
\hline hsa-miR-25-5p_MIMAT0004498 & $18,099.042$ & 0.918 & 1.890 & Up & 0.00473 & 0.04118 \\
\hline hsa-miR-30e-5p_MIMAT0000692 & 2296.889 & 0.897 & 1.862 & Up & 0.01612 & 0.08520 \\
\hline hsa-miR-30a-5p_MIMAT0000087 & 3027.454 & 0.849 & 1.801 & Up & 0.01892 & 0.09657 \\
\hline CM000680.1_15285_novel & 3128.361 & -2.349 & 5.093 & Down & 0.0000004213 & 0.00006 \\
\hline CM000668.1_36492_novel & 1075.400 & -2.202 & 4.602 & Down & 0.00122 & 0.02578 \\
\hline hsa-miR-1307-5p_MIMAT0022727 & 404.613 & -2.191 & 4.565 & Down & 0.00003364 & 0.00166 \\
\hline hsa-miR-375_MIMAT0000728 & 1029.877 & -2.058 & 4.164 & Down & 0.00036 & 0.01060 \\
\hline hsa-let-7i-5p_MIMAT0000415 & $58,413.753$ & -1.910 & 3.759 & Down & 0.000009499 & 0.00070 \\
\hline hsa-miR-134-5p_MIMAT0000447 & 156.437 & -1.802 & 3.486 & Down & 0.00258 & 0.02723 \\
\hline hsa-miR-328-5p_MIMAT0026486 & 116.074 & -1.657 & 3.154 & Down & 0.01198 & 0.07091 \\
\hline hsa-let-7f-5p_MIMAT0000067 & $58,027.774$ & -1.445 & 2.723 & Down & 0.00046 & 0.01131 \\
\hline hsa-miR-320a_MIMAT0000510 & 4133.844 & -1.432 & 2.698 & Down & 0.00185 & 0.02723 \\
\hline CM000668.1_35903_novel & 361.953 & -1.362 & 2.570 & Down & 0.01030 & 0.07084 \\
\hline hsa-miR-181b-5p_MIMAT0000257 & 1130.724 & -1.259 & 2.393 & Down & 0.00413 & 0.03818 \\
\hline hsa-miR-181b-5p_MIMAT0000257 & 1155.505 & -1.232 & 2.349 & Down & 0.00159 & 0.02723 \\
\hline hsa-miR-409-5p_MIMAT0001638 & 3315.486 & -1.158 & 2.232 & Down & 0.00948 & 0.07019 \\
\hline hsa-miR-744-5p_MIMAT0004945 & 1996.177 & -0.973 & 1.963 & Down & 0.01053 & 0.07084 \\
\hline hsa-miR-181a-5p_MIMAT0000256 & $34,050.461$ & -0.656 & 1.575 & Down & 0.01379 & 0.07560 \\
\hline hsa-miR-181a-5p_MIMAT0000256 & $34,050.461$ & -0.656 & 1.575 & Down & 0.01379 & 0.07560 \\
\hline
\end{tabular}

\subsection{Quantitative RT-PCR ( $q R T-P C R$ ) Validation of miRNAs Expression}

A second cohort of young male patients was recruited for qRT-PCR validation (Table 2), including two STEMI, two NSTEMI patients, and nine healthy controls from the original sRNA-seq cohort. Validation by qRT-PCR revealed a significant 8 -fold up-regulation of miR-183-5p in NSTEMI patients $(p=0.024)$ compared to healthy controls (Figure 2A). The expressions of miR-183-5p in NSTEMI patients were also significantly higher than those of the STEMI patients (Figure 2A). In STEMI patients, miR-134-5p, miR-15a-5p, and let-7i-5p were significantly down-regulated 5-fold ( $p=0.048), 7$-fold $(p=0.015)$ and 3.5-fold $(p=0.013)$, respectively, compared to healthy controls (Figure 2B-D), whereas miR-375 and miR-1307-5p were not significantly differentially expressed in STEMI and NSTEMI patients compared to the healthy controls (Figure 2E,F).

Since miR-183-5p, miR-134-5p, miR-15a-5p, and let-7i-5p were deregulated significantly in STEMI and NSTEMI patients, their expressions were compared further with those of the stable angina patients without ACS for more than one year. The expressions of miR-183-5p, miR-134-5p, miR-15a-5p, and let-7i-5p were not significantly deregulated in the stable angina patients compared to healthy controls (Figure 3). One-way analysis of variance (ANOVA) analysis followed by the Tukey multiple comparison test revealed that miR-183-5p is significantly up-regulated in NSTEMI compared to the stable angina patients (Figure 3A). In addition, the expression of miR-15a-5p and let-7i-5p were significantly down-regulated in patients with STEMI compared to those with stable angina (Figure 3C,D). The expression of miR-134-5p for STEMI patients was only significantly down-regulated when compared to healthy controls but not to the NSTEMI and stable angina groups (Figure 3B). 

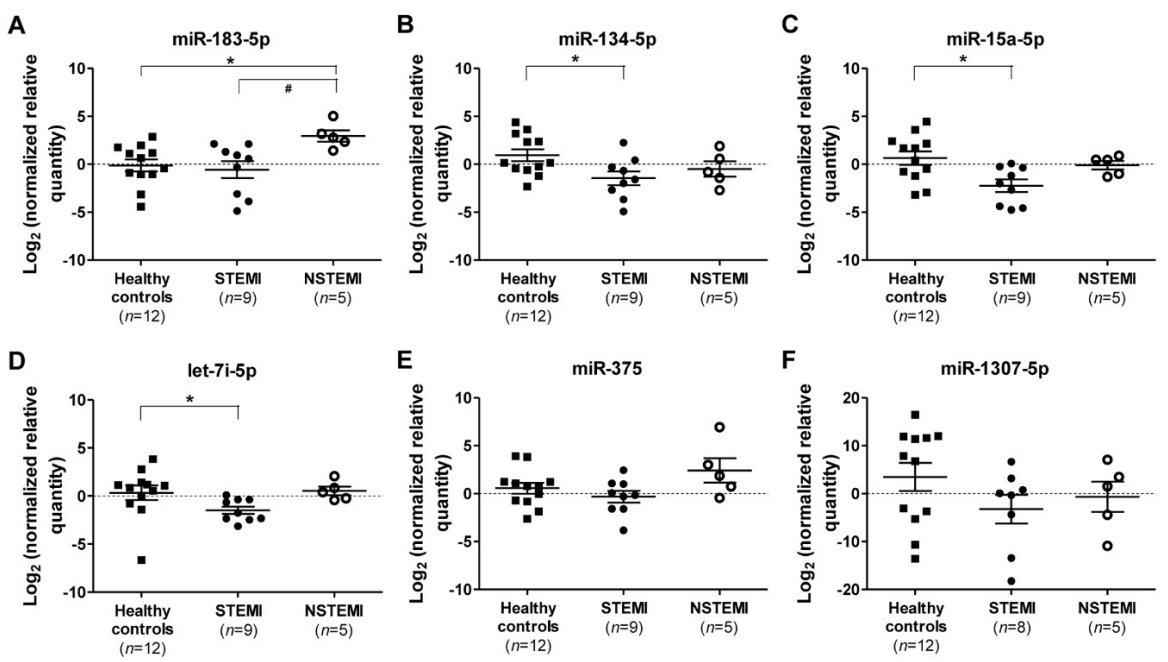

Figure 2. MiRNAs expression in ACS subtypes. $\log _{2}$ transformation of normalized relative quantity of (A) miR-183-5p, (B) miR-134-5p, (C) miR-15a-5p, (D) let-7i-5p, (E) miR-375, and (F) miR-1307-5p in healthy controls $(n=12)$, STEMI $(n=9)$, and NSTEMI $(n=5)$ patients. The expressions of the target miRNAs were normalized to both reference miRNAs, i.e., miR-320a and miR-17-5p. Data are shown as the geometric means $\pm 95 \% \mathrm{CI}$, confidence interval. $p$-values were calculated using one-way ANOVA followed by the Tukey multiple groups comparison test; * indicates $p<0.05$ compared to healthy control individuals; and ${ }^{\#}$ indicates $p<0.05$ compared to NSTEMI patients.

A

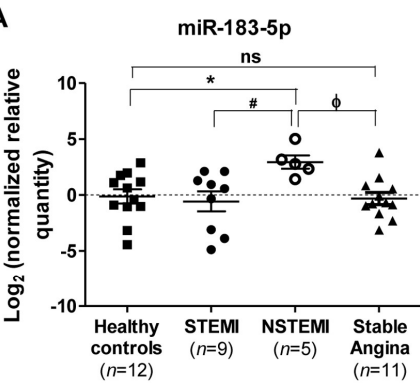

C

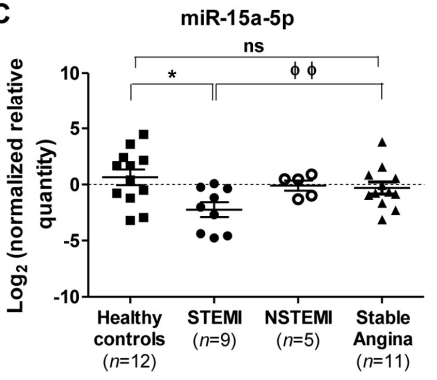

B

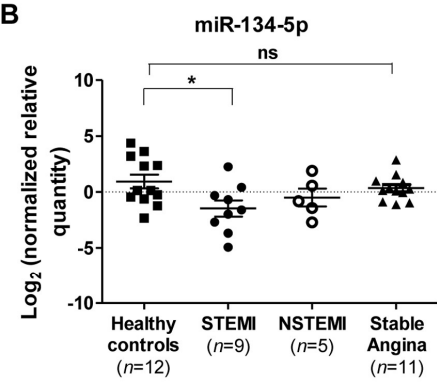

D

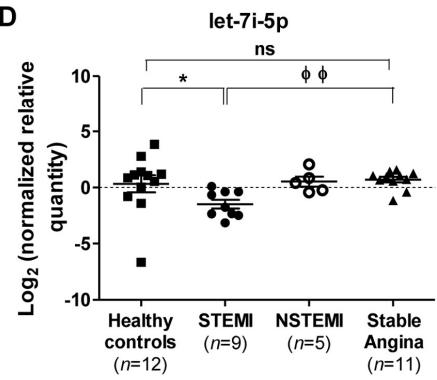

Figure 3. Comparison of miRNAs expression in individuals with ACS and stable angina. $\log _{2}$ transformation of normalized relative quantity of (A) miR-183-5p, (B) miR-134-5p, (C) miR-15a-5p, and (D) let-7i-5p in healthy controls $(n=12)$, STEMI $(n=9)$, NSTEMI $(n=5)$, and stable angina $(n=11)$ patients. The expressions of the target miRNAs were normalized to both reference miRNAs, i.e., miR-320a and miR-17-5p. Data are shown as the geometric means $\pm 95 \% \mathrm{CI}$, confidence interval. $p$-values were calculated using one-way ANOVA followed by the Tukey multiple groups comparison test; ns indicates not significant; ${ }^{*}$ indicates $p<0.05$ compared to healthy control individuals; ${ }^{\#}$ indicates $p<0.05$ compared to NSTEMI patients; $\phi$ indicates $p<0.05$ and $\phi \phi, p<0.01$ compared to stable angina patients. 


\subsection{Diagnostic Power of Plasma miRNAs in STEMI and NSTEMI Patients}

The diagnostic accuracy and discriminatory power of miR-183-5p, miR-134-5p, miR-15a-5p, and let-7i-5p for patients with STEMI and NSTEMI from healthy controls was determined using receiver operator characteristic (ROC) analysis, and illustrated by area under the curve (AUC) of ROC (Figure 4A and Table 4). MiR-183-5p scored a very high AUC value of $0.917(p<0.0001$; $95 \% \mathrm{CI}$, confidence interval 0.680 to 0.995 ) with sensitivity and specificity values of $100 \%$ and $75 \%$, respectively; this indicates a strong differentiation power of miR-183-5p for NSTEMI patients from healthy controls. However, miR-183-5p showed weaker discriminatory power for STEMI patients with an AUC value of 0.509 ( $p=0.947 ; 95 \%$ CI, 0.285 to 0.731 ) from the healthy controls (Figure 4 A(i) and Table 4). Nevertheless, miR-134-5p, miR-15a-5p, and let-7i-5p showed better differentiation power in discriminating STEMI patients from healthy controls with higher AUC values of 0.796 ( $p=0.004 ; 95 \%$ CI, 0.566 to 0.938$), 0.796$ ( $p=0.003 ; 95 \%$ CI, 0.566 to 0.938$)$, and 0.833 ( $p=0.0005 ; 95 \%$ CI, 0.608 to 0.958 ), respectively (Figure 4A(ii)-(iv), Table 4). Moreover, among these three miRNAs, the discriminatory power of let-7i-5p was the highest with a sensitivity value of $100 \%$ and a specificity value of $67 \%$ in differentiating STEMI patients from healthy controls (Table 4). Collectively, these findings reveal the strong discriminatory power of miR-183-5p in NSTEMI patients and miR-134-5p, miR-15a-5p, and let-7i-5p in STEMI patients from the healthy controls.

To investigate the discriminatory power of circulating miRNAs of ACS patients from patients with stable angina, AUC values for their respective ROC curves were obtained (Figure $4 \mathrm{~B}$ and Table 5). The discriminatory power of plasma miRNAs in STEMI against stable angina patients was highest in let-7i-5p, followed by miR-134-5p, miR-15a-5p, and miR-183-5p (Figure 4B(i) and Table 5). In differentiating NSTEMI from stable angina patients, miR-183-5p scored the highest discriminatory power compared to the other miRNAs, with the highest AUC value of $0.917(p<0.0001 ; 95 \% \mathrm{CI}, 0.680$ to 0.995 ), a sensitivity value of $100 \%$ and a specificity of $83 \%$ (Figure $4 \mathrm{~B}(\mathrm{ii})$ and Table 5 ).

Table 4. Discriminatory powers of plasma miRNAs for STEMI and NSTEMI patients against healthy controls.

\begin{tabular}{ccccccc}
\hline Patients & miRNAs & AUC & $\mathbf{9 5 \%}$ CI & $p$-Value & Sensitivity (\%) & Specificity (\%) \\
\hline \multirow{5}{*}{ STEMI } & miR-183-5p & 0.509 & 0.285 to 0.731 & 0.947 & 33.3 & 83.3 \\
& miR-134-5p & 0.796 & 0.566 to 0.938 & $0.004 * *$ & 66.7 & 83.3 \\
& miR-15a-5p & 0.796 & 0.566 to 0.938 & $0.003 * *$ & 100.0 & 58.3 \\
& let-7i-5p & 0.833 & 0.608 to 0.958 & $0.0005 * *$ & 100.0 & 66.7 \\
& miR-375 & 0.620 & 0.386 to 0.820 & 0.335 & 88.9 & 41.7 \\
miR-1307-5p & 0.698 & 0.455 to 0.880 & 0.103 & 100.0 & 58.3 \\
\hline \multirow{5}{*}{ NSTEMI } & miR-183-5p & 0.917 & 0.680 to 0.995 & $<0.0001 * * *$ & 100.0 & 75.0 \\
& miR-134-5p & 0.717 & 0.451 to 0.904 & 0.144 & 60.0 & 83.3 \\
& miR-15a-5p & 0.617 & 0.355 to 0.836 & 0.411 & 100.0 & 50.0 \\
& let-7i-5p & 0.583 & 0.325 to 0.812 & 0.592 & 80.0 & 83.7 \\
& miR-375 & 0.683 & 0.418 to 0.882 & 0.207 & 60.0 & 50.3 \\
\hline
\end{tabular}

Abbreviations: AUC, area under the curve of ROC; $95 \% \mathrm{CI}$, confidence interval. $P$-values and $95 \%$ confidence intervals $\left(95 \%\right.$ CI) were computed following the method of DeLong et al. (1988) [33]. ${ }^{* *}$ indicates $p<0.01 ;{ }^{* * *}, p<0.001$.

Table 5. Discriminatory powers of circulating miRNAs for STEMI and NSTEMI patients against stable angina patients.

\begin{tabular}{ccccccc}
\hline Patients & miRNAs & AUC & $\mathbf{9 5 \%}$ CI & $p$-Value & Sensitivity (\%) & Specificity (\%) \\
\hline \multirow{2}{*}{ STEMI } & miR-183-5p & 0.546 & 0.318 to 0.761 & 0.756 & 55.6 & 75.0 \\
& miR-134-5p & 0.769 & 0.535 to 0.922 & $0.027^{*}$ & 55.6 & 100.0 \\
& miR-15a-5p & 0.907 & 0.700 to 0.989 & $<0.0001^{* * *}$ & 100.0 & 66.7 \\
& let-7i-5p & 0.929 & 0.722 to 0.995 & $<0.0001^{* * *}$ & 100.0 & 81.8 \\
\hline \multirow{2}{*}{ NSTEMI } & miR-183-5p & 0.917 & 0.680 to 0.995 & $<0.0001^{* * *}$ & 100.0 & 83.3 \\
& miR-134-5p & 0.633 & 0.370 to 0.848 & 0.486 & 40.0 & 100.0 \\
& miR-15a-5p & 0.717 & 0.451 to 0.904 & 0.100 & 100.0 & 50.0 \\
& let-7i-5p & 0.618 & 0.348 to 0.843 & 0.525 & 60.0 & 81.8 \\
\hline
\end{tabular}

Abbreviations: AUC, area under the curve of ROC; $95 \%$ CI, confidence level. $P$-values and $95 \%$ CI were computed following the method of DeLong et al. (1988) [33]. * indicates $p<0.05 ;{ }^{* * *}, p<0.001$. 
A

(i)

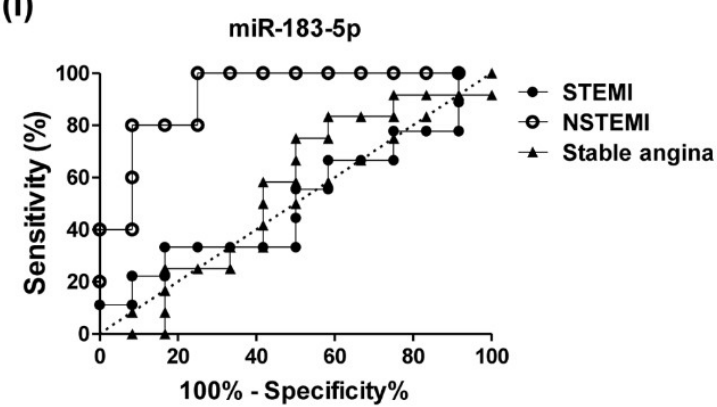

(iii)

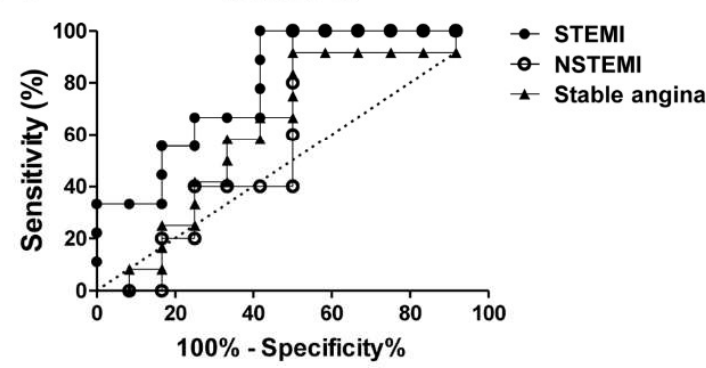

B

(i)

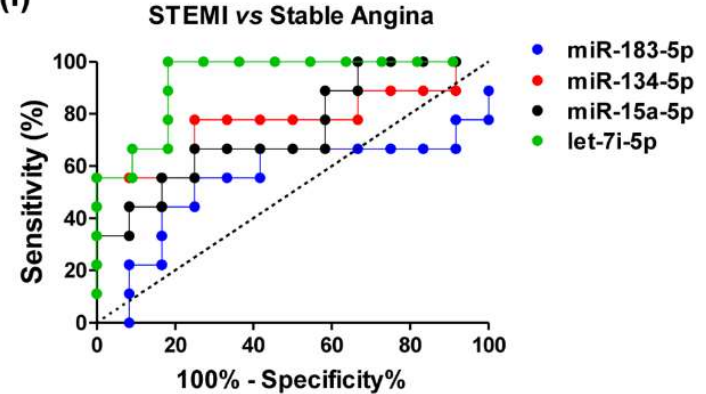

(ii)
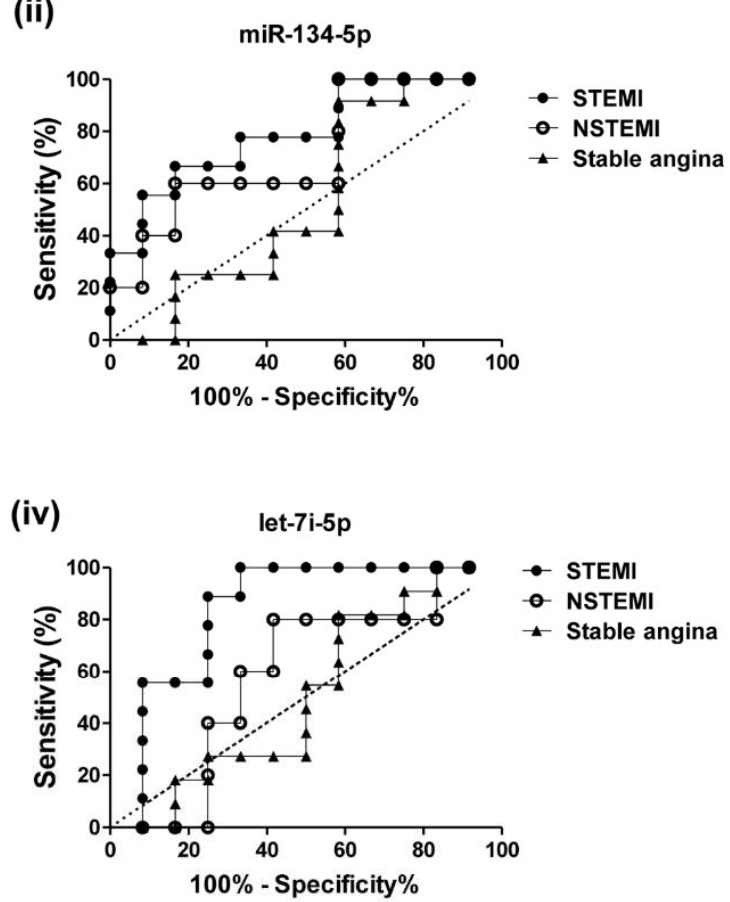

(ii)

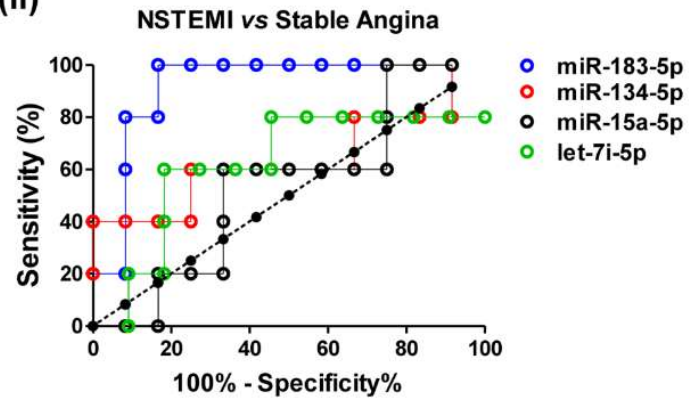

Figure 4. Discriminatory power of plasma miRNAs for ACS patients. (A) Receiver operator characteristic (ROC) curves for (i) miR-183-5p, (ii) miR-134-5p, (iii) miR-15a-5p and (iv) let-7i-5p in STEMI, NSTEMI and stable angina patients against healthy controls. (B) ROC curves for miR-183-5p, miR-134-5p, miR-15a-5p, and let-7i-5p in (i) STEMI and (ii) NSTEMI patients against patients with stable angina. ROC analysis was performed using GraphPad Prism version 5.0 (GraphPad Software, San Diego, CA, USA).

\subsection{Discriminatory Power of the miRNA Combination Panel}

An miRNA combination panel consisting of miR-134-5p, mR-15a-5p, and let-7i-5p was evaluated for its ability in differentiating STEMI patients from the healthy controls (Figure 5). Prior to the analysis, an miRNA score of the miRNA combination panel was calculated as described in the Methods section. The combination had a higher discriminatory power in differentiating STEMI patients from the healthy controls, with an AUC value of 0.935 ( $p<0.0001 ; 95 \%$ CI, 0.737 to 0.996$)$, a sensitivity of $100 \%$ and a specificity of $83 \%$ (Figure $5 \mathrm{~B}$ ) when compared to that of the individual miRNAs (Figure $4 \mathrm{~A}$ ). Furthermore, this miRNA combination panel also improved the differentiation of STEMI patients from subjects with stable angina, with an AUC value of 0.990 ( $p<0.0001 ; 95 \%$ CI, 0.814 to 1.000$)$, a sensitivity of $100 \%$ and a specificity of $91 \%$ compared to that of the individual miRNAs (Figure 5C). 

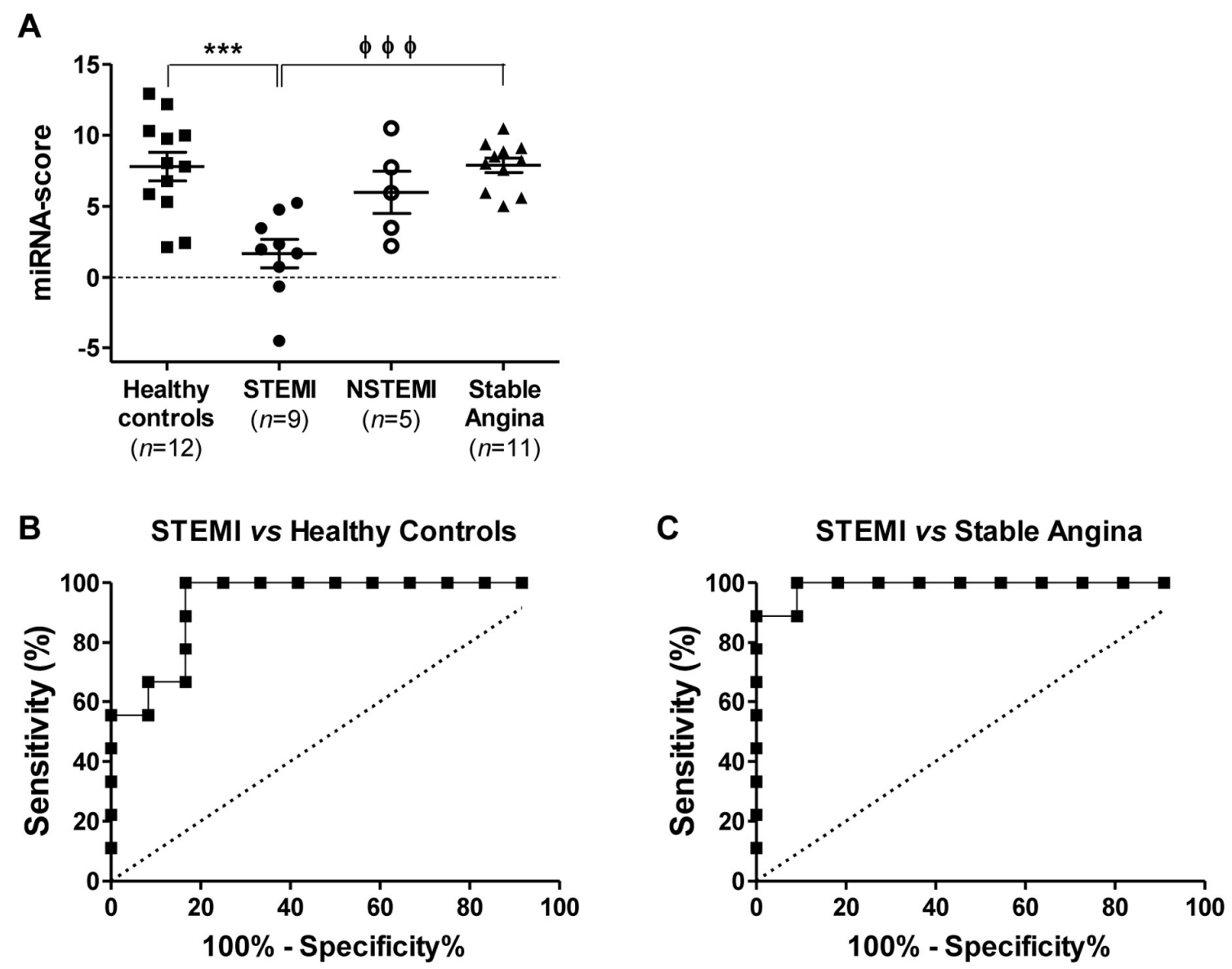

Figure 5. Discriminatory power of miRNAs combination panel for STEMI from stable angina patients. (A) miRNA-score of the miRNAs combination panel (miR-134-5p, miR-15a-5p, and let-7i-5p) is presented as means \pm standard error of mean (SEM) in healthy controls $(n=12)$, patients with STEMI $(n=9)$, NSTEMI $(n=5)$, and stable angina $(n=11)$; ${ }^{* * *}$ indicates $p<0.001$ compared to healthy control individuals; and $\phi \phi \phi$ indicates $p<0.001$ compared to stable angina patients. Receiver operator characteristic (ROC) curves for the miRNAs combination panel in STEMI patients against (B) healthy controls or $(\mathbf{C})$ patients with stable angina.

\subsection{Correlation between Circulating miRNAs, Age, and Troponin I and CK-MB Levels}

To determine whether the expression levels of miRNAs correlate with age, plasma troponin I, or CK-MB levels of STEMI and NSTEMI patients, Pearson correlation analyses were performed. The expression of miR-134-5p was inversely correlated with plasma troponin I levels in ACS patients (Pearson $r=-0.586, p=0.035$, Figure 6A). In addition, correlation with plasma troponin I levels improved with the miRNA combination panel of miR-134-5p, miR-15a-5p, and let-7i-5p (Pearson $r=-0.611, p=0.027$, Figure 6A). The expression of miR-134-5p was moderately, but not significantly $(p=0.07)$, correlated with the age of patients with a Pearson $r$ value of 0.5 (Figure 6B). For plasma CK-MB levels or interval time of blood collection in ACS patients, no significant correlation was found with circulating amounts of miR-183-5p, miR-134-5p, miR-15a-5p, and let-7i-5p (Figure 6C,D). 
A
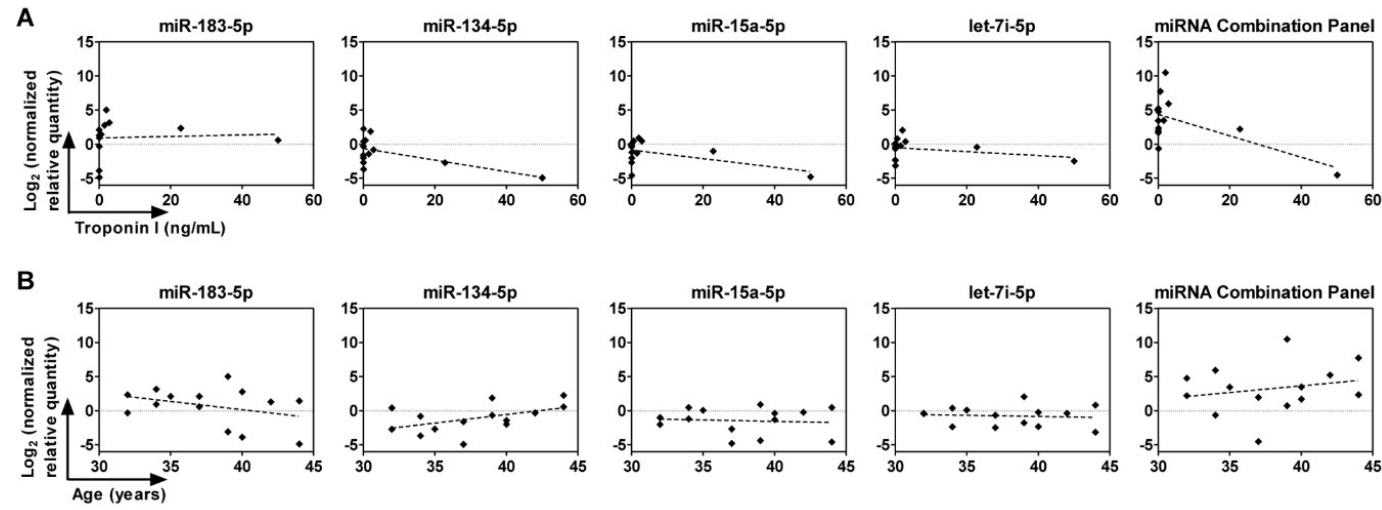

C
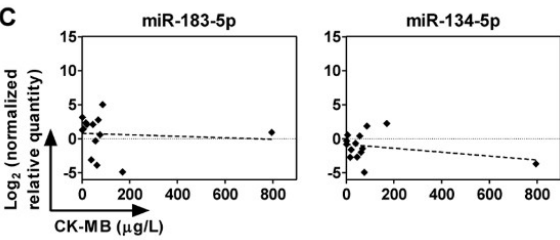

D
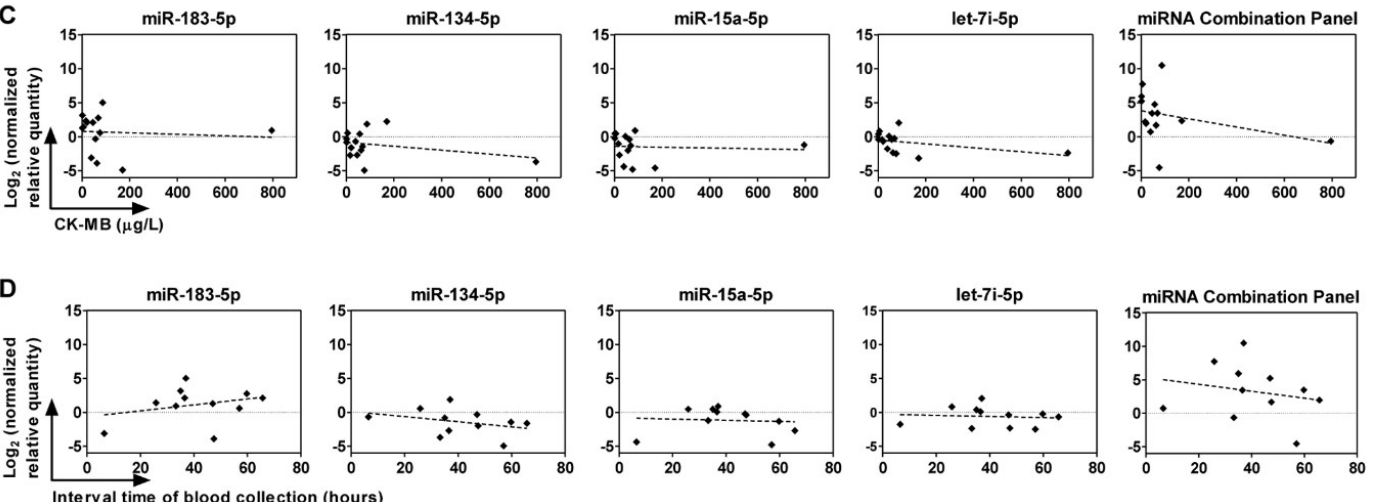

Figure 6. Correlation of plasma miRNAs with plasma cardiac biomarkers, age, and time of blood withdrawal. Pearson correlation analyses were conducted to determine the association of expressions of miRNAs with (A) troponin I levels, (B) age, (C) creatine kinase-myocardial band (CK-MB) levels in STEMI and NSTEMI patients, and (D) interval time of blood collection. The miRNA combination panel consists of miR-134-5p, mR-15a-5p, and let-7i-5p.

\subsection{Expressions of miRNAs in Tissues and Organs}

The expressions of miR-183-5p, miR-134-5p, miR-15a-5p, and let-7i-5p across different tissues were estimated, using the miRNA search analysis module on microRNA Expression and Sequence Analysis database (mESAdb) (http://konulab.fen.bilkent.edu.tr/mirna/mirna.php) to determine their potential tissues of origin [34]. The expression of miR-183-5p is the lowest across all tissues in comparison to miR-134-5p, miR-15a-5p, and let-7i-5p (Figure 7A). MiR-183-5p is significantly enriched in the heart, liver, and skeletal muscle $(p<0.05)$; miR-15a-5p is also significantly enriched in the heart as well as in the bladder, colon, kidney and the immune system tissues (bone marrow, lymph node, and spleen, $p<0.05$ ) whereas both miR-134-5p and let-7i-5p are abundantly found in the brain and frontal cortex.

\subsection{Predicted Target Genes of miRNAs Are Enriched in Metabolic Pathways}

Significant deregulation of miR-134-5p, miR-15a-5p, and let-7i-5p was observed in young STEMI patients, therefore the union set of predicted genes for miR-134-5p, miR-15a-5p, and let-7i-5p were selected for enrichment analysis using Enrichr [35,36], whereby the predicted genes for miR-183-5p were submitted for enrichment analysis as described. Pathway enrichment analysis suggested that the predicted target genes of miR-134-5p, miR-15a-5p, and let-7i-5p were enriched in the Ras/MAPK, PI3K-AKT signaling pathway, angiogenesis, integrin, and Wnt signaling pathways which regulate cell proliferation, cell survival, and other basic developmental processes (Figure 7B(i)). Enrichment analysis in the Disease/Drug enrichment category in Enrichr suggested the presence of interaction between these predicted genes with most of the risk factors of cardiovascular disease such as low-density 
lipoprotein (LDL), blood pressure, and body fat distribution as listed in Genotypes and Phenotypes database (Figure $7 \mathrm{~B}(\mathrm{i})$ ). In addition, the predicted target genes of miR-183-5p include those in Hedgehog and endothelin signaling pathways, metabolic pathways, and are associated closely with HDL, LDL, and cholesterol metabolism (Figure 7B(ii)). The enrichment analysis of the list of predicted genes for miR-134-5p, miR-15a-5p, let-7i-5p, and miR-183-5p, hence revealed that these miRNAs and their predicted mRNA targets have roles aligned to events in the pathogenesis of ACS.

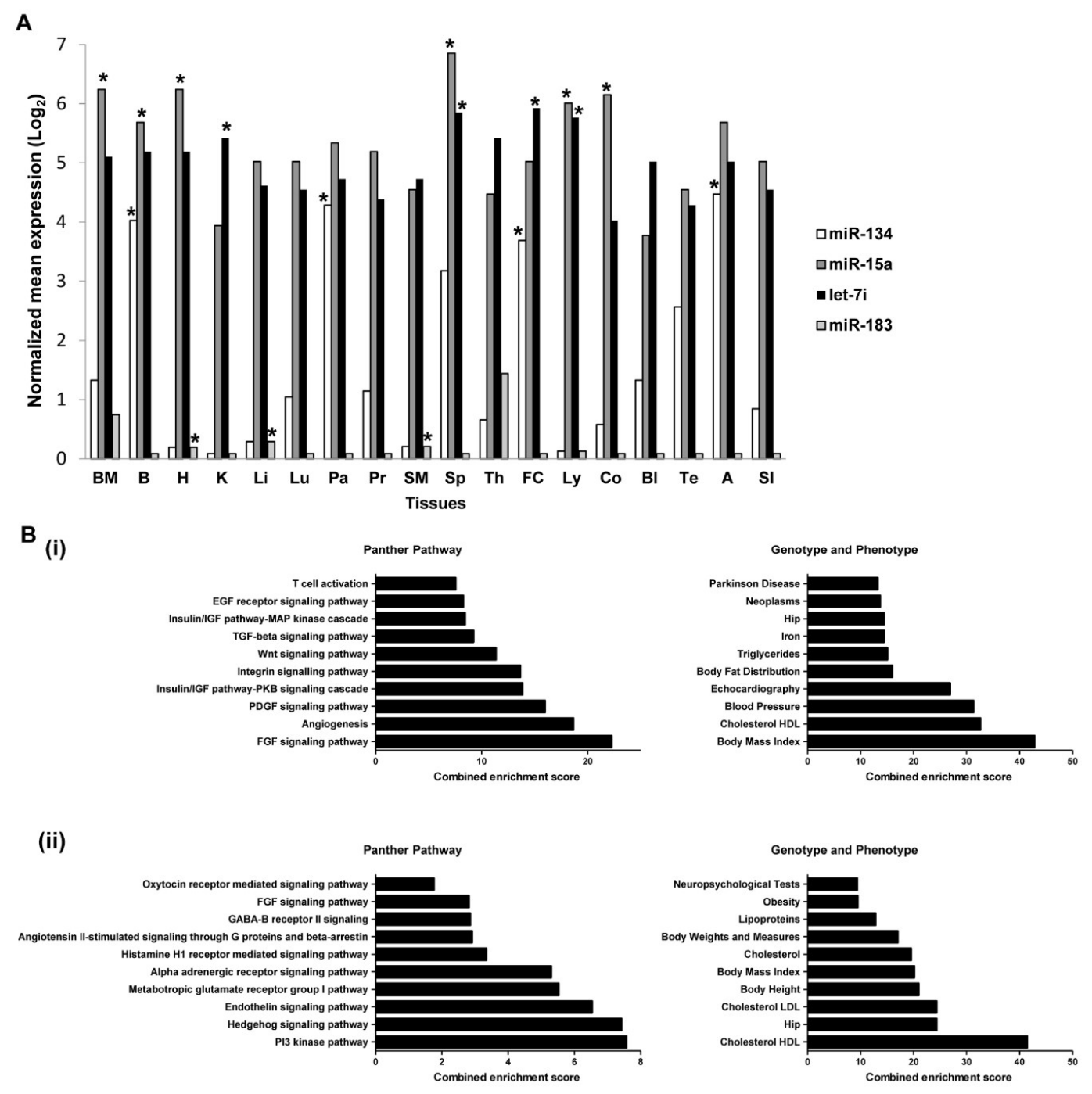

Figure 7. Expressions of miRNAs in tissues and enrichment analysis for predicted target genes of miRNA candidates. (A) Tissues expression analysis of miRNAs was performed using the online database of microRNA Expression and Sequence Analysis database (mESAdb) (http://konulab.fen. bilkent.edu.tr/mirna/mirna.php). ${ }^{*} p<0.05$ depicts significant enrichment in the respective tissue. (B) Panther pathway and Genotypes and Phenotypes enrichment analysis for: (i) union set of predicted target genes for miR-134-5p, miR-15a-5p and let-7i-5p and (ii) predicted target genes for miR-183-5p were performed using the Enrichr online algorithm program. Combined enrichment scores which integrate $p$-value and $z$-score information as described in Section 4.8 were used to rank the enrichment term in analysis. The top 10 enrichment terms are reported for each bar graph. Abbreviations: BM, Bone Marrow; B, Brain; H, Heart; K, Kidney; Li, Liver; Lu, Lungs; Pa, Pancreas; Pr, Prostate; SM, Skeletal muscle; Sp, Spleen; Th, Thymus; FC, Frontal Cortex; Ly, Lymph node; Co, Colon; Bl, Bladder; Te, Testicle; A, Adrenal gland; SI, Small intestine; HDL, high-density lipoproteins; and LDL, low-density lipoproteins. 


\section{Discussion}

The role of miRNAs in the pathophysiology of atherosclerosis and CAD has received increasing attention. MiRNAs modulate endothelial function, communication between endothelial cells and vascular smooth muscle cells, differentiation of the latter, and regulation of inflammatory cells in blood vessels, all of which are events leading to the development of CAD [37,38]. Deregulated expressions of cardiac specific miRNAs such as miR-1, miR-499, miR-133a/b, miR-208a/b, and miR-145 have been established in patients with stable CAD, ACS, and AMI, and their roles in events (regulation of endothelial function, differentiation of vascular smooth muscle cells, and plaques stabilization) leading to the development of these diseases are documented [39]. However, some cardiac-specific miRNAs such as miR-1, miR-133b, and miR-499 may have less discriminative power for AMI and unstable angina as they can also be released from injured skeletal muscles and thus conditions other than acute myocardial necrosis may influence their circulating levels [40]. Despite this limitation, in a large cohort of ACS patients, the levels of miR-132, miR-140-3p, and miR-210 predicted mortality, further highlighting the value of using miRNAs for disease prognosis [41], and underscoring the need for further identification of miRNAs for disease stratification and more accurate diagnosis.

The present study was undertaken to identify plasma miRNAs in young individuals diagnosed with ACS in Malaysia. From an initial list of top 13 up-regulated and 16 down-regulated miRNAs identified by sRNA-seq with differential expression analysis of FDR $<10 \%$ from the STEMI group, subsequent validation in the qRT-PCR cohort revealed significantly lower expressions of miR-134-5p, miR-15a-5p, and let-7i-5p in patients with STEMI, and higher expression of miR-183-5p in NSTEMI patients, compared to healthy controls. However, cardiac-specific miRNAs (e.g., miR-1, miR-208a, miR-208b, miR-133a, miR-133b, and miR-499), smooth muscle-enriched miR-143 and miR145 (released from injured cardiomyocytes), inflammation-associated miR-155, vascular protective miR-126 and endothelial-enriched miR-17 and 92a [40,42-51] were absent in the list of significantly deregulated plasma miRNAs as identified by sRNA-seq, possibly because of low sequencing reads. Indeed, qRT-PCR quantification revealed that these miRNAs are present in relatively low abundance in the plasma of ACS subjects [22].

Previously, let-7i-5p and miR-15a-5p were reported to be deregulated in CAD [52-54]. Significant down-regulation of let-7i was observed in elderly patients with stable CAD in comparison to healthy controls [52,54]. However, in the present cohort of young patients, let-7i-5p did not discriminate stable angina from healthy controls but instead identified the STEMI from the healthy control and stable angina groups. Members of the let-7 family share the same seed sequence and are conserved [55]. It has been reported that let- $7 \mathrm{~g}$ preserves endothelial function and suppresses inflammation induced by metabolic deregulation [56]. Indeed, pathway enrichment analysis showed that targets of let-7i-5p are involved in angiogenesis and metabolic pathways. In addition, this miRNA is also significantly enriched in lymph nodes and the spleen, which is suggestive of its potential role in inflammation.

The expression of miR-15a-5p is up-regulated in the plasma of elderly stable CAD (non-occlusive) patients when compared to healthy controls [53]. However, its differential expression was significantly different between the present young patients with stable angina (occlusive) and healthy controls. MiR-15a-5p has instead discriminated the STEMI from the healthy control and stable angina groups. These observations suggest that age factors or the differences between CAD presentations (occlusive versus non-occlusive) may lead to the differential expression of these miRNAs. Likewise, miR-15a-5p is also abundantly expressed in the bone marrow, lymph nodes and the spleen and, together with let-7i-5p and miR-134-5p, addresses predicted targets genes that are involved in endothelin signaling pathways, metabolic pathways, and lipid metabolism. In addition, miR-15a-5p is also significantly enriched in the heart, suggesting that it could potentially be cardio-specific. The ability of both let-7i-5p and miR-15a-5p in discriminating STEMI from stable angina and healthy controls warrants further evaluation of their potentials for the diagnosis of STEMI.

MiR-134-5p has been identified in plasma or serum of patients with STEMI, NSTEMI, unstable angina pectoris, acute myocardial infarction, and acute pulmonary embolism [17,18,20]. An earlier 
study showed a 6-fold increase in miR-134-5p expression, six hours after the onset of symptoms [57] while a kinetic study reported its peaked expression (6-fold) on admission [20]. In the present study, the expression of miR-134-5p was lower in STEMI and NSTEMI patients compared to healthy controls. The expression was measured approximately $36 \mathrm{~h}$ after the onset of symptoms, an average time needed for stabilization of the patients in the clinical ward, examination by ECG and percutaneous coronary angiogram. Nevertheless, the expression of miR-134-5p remained detectable and could discriminate the STEMI patients from healthy controls and stable angina patients with a relatively high AUC value, in agreement with a previous report [22]. Pearson analysis revealed no correlation between the expression of miR-134-5p and the time after the onset of symptoms at which blood was collected. However, one could still argue that a late sampling time may have contributed to the lower expression level of miR-134-5p in the present study, compared to earlier finding [22]. The kinetic study mentioned above [20] showed a 1.6-fold increase in expression $22 \mathrm{~h}$ after symptoms onset in patients with acute myocardial infarction; thus, despite a gradual decline in miR-134-5p expression with time, it still can be expected to be above baseline at the moment that blood was sampled for the present experiments. Hence, contrary to the higher expression reported in older ACS patient group [20,22], miR-134 levels are indeed lower in the young ACS group compared to healthy controls. MiR-134-5p accelerates atherosclerosis by promoting lipid accumulation and inflammatory responses following induction of lipoprotein lipase in macrophages [58], which explains its higher (3.5-fold) expression in peripheral blood mononuclear cells isolated from patients with unstable angina [17]. Endothelium-expressed miRNAs such as miR-126, -17, -92a, and inflammatory-associated miR-155 are also reduced in the blood of patients with stable CAD, suggesting that these miRNAs are taken up into the atherosclerotic lesions [52]. In this regard, it has been reported that macrophages in atherosclerotic lesions express scavenger receptors (SRs) for the uptake of oxidized low-density lipoproteins and several miRNAs have been shown to regulate SRs in atherosclerosis [59]. Hence, it appears worthwhile to investigate the role of miR-134-5p from this aspect as well. Combining miR-134-5p with miR-15a-5p and let-7i-5p improved the power of discriminating STEMI patients from those with stable angina with the highest AUC value compared to those of the individual miRNAs. This is not surprising given that each miRNA has multiple targets and multiple miRNAs can act in a cooperative way to modulate events related to CAD pathogenesis as indicated by the present target genes enrichment analysis. Thus, the use of a combination of multiple miRNAs could achieve greater diagnostic power for ACS.

MiR-183-5p plays an important role in maintaining endothelial barrier function and vascular permeability [60], even though it is better known as an oncomir [61-64] and is overexpressed in tumor tissues. MiR-183-5p regulates the tightness of the blood-nerve barrier [65] by regulating claudin- 5 protein, an endothelial cell-specific tight junction component [66]. The expression of miR-183-3p is down-regulated in plasma of heart failure patients, suggesting that miR-183 could potentially be a marker of heart failure [67]. Indeed, the present tissue expression analysis revealed that miR-183 is enriched in the heart and skeletal muscle. The significant up-regulation of miR-183-5p in plasma of NSTEMI patients in the present study could potentially be related to its effects on the endothelial barrier, particularly on the tight junction proteins during atherogenesis, but this warrants future investigations. If indeed miR-183-5p is involved in atherogenesis, it could potentially serve as an early marker for ACS patients without malignancy. Nevertheless, since it is enriched in skeletal muscle, its circulating levels may be impacted by conditions involving injury of those tissues.

Several limitations of the present study merit consideration. First, the study was limited by a small cohort size given that we could recruit only a small number of patients below 45 years of age due to the relatively lower prevalence of ACS in younger age groups (23\%) compared to older age groups $(77 \%)$. Due to this low number, we were also unable to stratify the cohort according to ethnic groups to further identify ethnicity-related miRNAs. The expression of miR-375 and its CpG methylation is significantly different between the Han and Kazak ethnic groups of type 2 diabetes patients [68]. MiR-375 was also identified by the present sRNA-seq but further evaluation of its expression by qRT-PCR yielded insignificance. In another example, polymorphism within the miR-155 binding site on the $3^{\prime} \mathrm{UTR}$ of 
its target gene, angiotensin II type 1 receptor (AGTR1) has been identified in different ethnic groups. This polymorphism can disrupt miR-155 regulation of AGTR1, leading to increased expression which contributes to vasoconstriction and increases the risk for cardiovascular disease [69,70]. In Malaysia, the Indian ethnic group has the highest prevalence of ACS followed by the Malay and Chinese groups and hence, a larger cohort that enables ethnic group stratification would be required to determine whether or not the miRNAs identified in the present study are ethnically differently distributed.

Second, we observed discrepancies between the expression trend for miR-183-5p and miR-15a-5p analyzed by sRNA-seq and qRT-PCR. The sRNA-seq analysis showed up-regulation of miR-183-5p for STEMI patients but qRT-PCR validation revealed increased miR-183-5p expression only in NSTEMI patients. Likewise, for miR-15a-5p, the sRNA-seq analysis showed up-regulation in STEMI patients but the qRT-PCR validation instead revealed down-regulation in STEMI patients. These discrepancies probably reflect the higher sensitivity and sequence-specificity of qRT-PCR, which can quantify absolute copies numbers of specific mRNA or small RNA species, whereas, with the RNA-seq method, miRNA quantification is expressed as a value relative to the total number of sequences reads of a given sample. Hence, for miRNAs with a high variance in expression distribution across samples, comparisons between the latter may not yield reliable results [71].

Third, we did not perform statistical correction for confounding factors as the number of subjects in each group was low. It has been reported that plasma levels of cardiomyocyte-specific miRNAs such as miR-208b and miR-499 are not affected by a wide range of clinical confounders such as age, gender, body mass index, kidney function, systolic blood pressure, and white blood cell count [45]. However, confounding factors such as medication (including statins) influence the events involved in the pathophysiology of cardiovascular diseases by regulating the expression of particular miRNAs. For example, simvastatin can decrease miR-155 expression by disrupting the mevalonate-geranylgeranyl-pyrophosphate-RhoA signaling pathway leading to endothelial nitric oxide synthase expression and endothelium-dependent vasodilatation [72]. Atorvastatin induces let-7i expression and down-regulates toll-like receptor 4 signaling in monocytes from CAD patients thereby blunting immune responses [54]. Similarly, in statin-treated unstable angina patients, miRNAs such as miR-15b, -17, -20a and -93 that primarily target genes involved in angiogenesis are down-regulated, in line with the atheroprotective effects of statins in these patients [73]. Hence, these findings highlight the importance of statistical corrections for the effect of medications in future larger cohort studies. Last, the present study did not perform time course measurements of the changes in the levels of the identified miRNAs, which would provide the optimal detection window to identify their dynamic contribution.

\section{Materials and Methods}

\subsection{Participants}

Recruitment of participants was conducted at the University Malaya Medical Centre, Kuala Lumpur, Malaysia in accordance to the approved guidelines by the local Medical Ethics Committee (Ethics No. 889.6, November 2011). Informed consent was obtained from all subjects.

For sRNA-seq, 14 ACS male patients below 45 years of age, clinically diagnosed with either NSTEMI or STEMI, and 14 gender- and age-matched control subjects were enrolled in this first cohort. The diagnosis of STEMI and NSTEMI in this study is based on local guidelines. STEMI is defined as persistent ST segment elevation $\geq 1 \mathrm{~mm}$ in two contiguous electrocardiographic leads, or the presence of a new left bundle branch block in the setting of positive cardiac markers. NSTEMI is defined as the occurrence of acute myocardial infarction in the setting of positive cardiac markers, with or without accompanying electrocardiographic changes other than ST-segment elevation $[74,75]$. The healthy controls had proven normal coronary via invasive percutaneous coronary angiogram.

For qRT-PCR validation, 14 ACS patients, 12 healthy control subjects and 12 aged-matched stable angina patients were recruited in this second cohort. The stable angina patients previously had CAD 
confirmed by percutaneous coronary angiogram but had not presented with acute episodes for more than one year.

Exclusion criteria for the ACS and stable angina groups include previous history of cardiovascular diseases such as myocardial infarction, heart failure and cardiomyopathy. For the selection of healthy subjects, chronic alcoholics, smokers and those with family history of cardiovascular disease (CVD) or on CVD medications and familial hypercholesterolemia were excluded. Only males were included in the present study to preserve data homogeneity.

\subsection{Isolation of Human Plasma}

For confirmed cases of STEMI, NSTEMI and stable angina, blood collection was performed within $36 \mathrm{~h}$ after admission. Whole blood samples $(6 \mathrm{~mL})$ were collected by direct venous puncture into tubes containing ethylenediaminetetraacetic acid (EDTA), centrifuged at $2000 \times g$ for $15 \mathrm{~min}$ after which the supernatant (plasma) was carefully transferred into an RNase-free tube for extraction of miRNAs. The resultant plasma was aliquoted into cryopreservation tubes and stored at $-80{ }^{\circ} \mathrm{C}$ until use.

\subsection{MiRNA Extraction}

MiRNAs were extracted from plasma using the miRNeasy serum/plasma kit (Qiagen, Hilden, Germany), and finally eluted into $14 \mu \mathrm{L}$ of RNase-free water according to the manufacturer's instructions. Subsequently, the miRNA samples were concentrated using refrigerated CentriVap benchtop centrifugal concentrator (Labconco Corporation, Kansas City, MI, USA). An Agilent Small RNA Kit was used to verify miRNA quality and quantity using Agilent 2100 Bioanalyzer (Agilent Technologies, Santa Clara, CA, USA).

\subsection{Small-RNA Sequencing (sRNA-seq)}

Library preparation and sRNA sequencing was performed on each plasma sample using the Illumina platform, following the manufacturer's protocol (Illumina Inc., San Diego, CA, USA). Small RNA libraries were constructed using a TruSeq Small RNA Sample Preparation kit (Illumina) according to the manufacturer's instructions. Briefly, small RNA samples (18-30 nt) were gel-purified and ligated to the $5^{\prime}$ and $3^{\prime}$ adapters, followed by RT-PCR for cDNA library construction and incorporation of index tags. The cDNA library fragments were purified, separated on a PAGE gel and loaded on an Agilent Technologies 2100 Bioanalyzer to check size, purity, and concentration. Libraries were sequenced using Illumina HiSeq2000 at the BGI-Shenzhen (Shenzhen, Guangdong, China).

\subsection{Sequencing Data Analysis}

The read data were assessed and pre-processed using FastQC (http://www.bioinformatics. babraham.ac.uk/projects/fastqc) and FASTX-Toolkit (http://hannonlab.cshl.edu/fastx_toolkit), respectively. Briefly, the $3^{\prime}$ adapter sequences and low quality bases $(<Q 30)$ were trimmed. All reads that were shorter than $18 \mathrm{bp}$ or containing unknown bases $(\mathrm{N})$ were discarded. For each dataset, reads with identical sequences were collapsed to give a set of non-redundant reads (nr-reads). The nr-reads were then aligned to the human genome (GRCh37) using the mapper module from miRDeep2 [76] by allowing one mismatch. Unmapped reads/nr-reads or reads/nr-reads mapped to more than five regions in the human genome were filtered. The distribution of mapped reads was analyzed by cross-checking with miRBase v20 (http://www.mirbase.org/), Ensembl annotations and Rfam v11 database (http://rfam.xfam.org/). Finally, the miRDeep2 program (https:/ / www.mdc-berlin.de/content/mirdeep2-documentation) [76] was used to identify known miRNAs (based on miRNA data from miRBase v20) to predict novel miRNAs and to summarize the read counts for each miRNA in every sample. The comma separated values (csv) files for miRNA expression from mirDeep2 were obtained for further analysis. Differential expression of the miRNA-Seq raw count data was assessed using the BioC/R package DESeq2 (https: / / bioconductor. org/packages/release/bioc/html/DESeq2.html) [32]. The data were adjusted to a common scale 
by normalizing them for different library sizes. The data (miRNA) dispersion from the mean was estimated, which provides the basis for inference. $p$-values were adjusted using multiple testing with the Benjamini and Hochberg (1995) approach by applying the FDR of $10 \%$ [77]. The list or miRNAs with adjusted $p$-values were filtered at $p=0.1$.

\subsection{Validation of miRNA by $q R T-P C R$}

To validate the result of sRNA-seq data analysis, two-step qRT-PCR was performed to quantitate the expression of selected miRNAs. For reverse transcription, a total input of $10 \mathrm{ng}$ of total RNA was used to synthesize cDNA using a Taqman miRNA Reverse Transcription Kit according to the manufacturer's instructions (Applied Biosystems, Foster City, CA, USA). Taqman miRNA Assay for miR-183-5p (Assay ID: 002269), miR-134-5p (Assay ID: 001186), miR-15a-5p (Assay ID: 000389), let-7i-5p (Assay ID: 002221), miR-375 (Assay ID: 000564) and miR-1307-5p (Assay ID: 47256_mat) were purchased from Applied Biosystems. Taqman Fast Advance PCR Master Mix (Applied Biosystems) was used to perform the real-time RT-PCR. As it is reported that specific small nuclear RNA and small nucleolar RNA such as RNU44, RNU68 and RNU6 are highly variable or not detectable in human plasma $[61,62]$ and there is still no consensus on a suitable reference miRNA that can be used for qRT-PCR normalization, candidate reference miRNAs such as miR-320a (Assay ID: 002277) and miR-17-5p (Assay-ID: 000393) were selected as endogenous references based on their consistent expressions in sRNA-seq analysis. The expression stability of both reference miRNAs were also analyzed using geNorm and normalization by multiple reference genes was performed as proposed by Hellemans et al. (2007) [78,79]. Briefly, normalized relative quantity (NRQ) values were obtained by dividing the relative quantity (RQ) of the target miRNA with a normalizing factor (NF). NF was calculated from the geometric mean of RQ of the two reference miRNAs in each sample. $R Q$ of target miRNAs in each sample was calculated using the equation: $R Q=E^{\Delta C t}$ and $\Delta \mathrm{Ct}=\mathrm{Ct}_{\text {mean sample }}-\mathrm{Ct}_{\text {sample }}$ whereby, $\mathrm{E}$ refers to the amplification efficiency of the primer and $\mathrm{Ct}$ refers to the cycle threshold value in qRT-PCR. $\log _{2}$-transformed NRQ values, representing the expression of target miRNAs were used to plot graphs.

\subsection{Tissue Expression Analysis of miRNA Candidates}

The expressions of miR-183-5p, miR-134-5p, miR-15a-5p, and let-7i-5p across different tissues were analyzed using the miRNA search analysis module on mESAdb [34] which is accessible at http://konulab.fen.bilkent.edu.tr/mirna/mirna.php. Normalized mean expressions obtained from a dataset comprising of normal human tissues and organs by Baskerville et al. [80] was analyzed. $p<0.05$ depicts significant enrichment in the respective tissue.

\subsection{Target Genes Prediction and Gene List Enrichment Analysis for miRNA Candidates}

The target genes of miR-183-5p, miR-134-5p, miR-15a-5p and let-7i-5p were predicted using TargetScan [81] database. The target genes predicted were selected for subsequent pathway and gene ontology enrichment analysis using Enrichr [35,36]. Adjusted $p$-values, $z$-score, and combined enrichment score were computed by Enrichr. The combined enrichment score was described as a combination of the $p$-value and $z$-score calculated as $\mathrm{c}=\ln (\mathrm{p}) \times z$, whereby, $\mathrm{c}$ is the combined enrichment score, $p$ is the $p$-value computed by Fisher's exact test and $z$ is the $z$-score computed in order to access the deviation from the expected rank. The combined enrichment score was used to rank the enrichment terms in the analysis.

\subsection{Statistical Analysis}

Quantitative data were first evaluated to determine whether or not they followed Gaussian distribution using the D'Agostino and Pearson omnibus and Shapiro-Wilk normality test [82-85]. For $p$-value greater than the alpha level of 0.05 , the null hypothesis that the data reflect a normally distributed population cannot be rejected. Therefore, one-way ANOVA followed by the Tukey multiple 
groups comparison test was performed for normally distributed data whereas the non-parametric Kruskal Wallis test was used for data not distributed normally. In addition, qualitative data were compared using the Chi-Square test. Statistical analysis and $p$-values were computed using GraphPad Prism version 5.0 (GraphPad Software, San Diego, CA, USA). Statistical significance of differences was accepted at $p<0.05$.

ROC curve analysis and AUC were performed to discriminate healthy controls from patients with STEMI, NSTEMI or stable angina and to investigate the diagnostic accuracy of selected miRNAs. Standard errors of AUCs and 95\% confidence intervals (95\% CI) were computed following the method of DeLong et al. (1988) [33]. Based on ROC analysis, the sensitivity and specificity of miRNAs were evaluated via cut-off points obtained from the Youden index computed using MedCalc software version 16.8.4 (MedCalc Software, Ostend, Belgium) [20,86]. In addition, correlation analyses between the miRNAs with patients' age, plasma troponin I and CK-MB levels were evaluated using Pearson's correlation coefficient. To perform ROC and Pearson's correlation analyses for the miRNA combination panel (miR-134-5p, miR-15a-5p and let-7i-5p), a miRNA score representing the cumulative expression of each miRNA in the panel was computed first as described by Goren et al. (2012), whereby the score for each sample is the sum of the inverted-normalized signals of each individual miRNA adjusted by subtracting a constant (the minimal score) so that the range of scores starts at 0 [87].

\section{Conclusions}

In conclusion, findings from sRNA-seq and qRT-PCR revealed a novel miRNA expression profile in young individuals with ACS compared to those of previous studies in patients of older age groups. MiR-183-5p emerged as the circulating miRNA that can significantly discriminate NSTEMI from STEMI, stable angina patients or healthy normal individuals whereas miR-134-5p could discriminate STEMI patients from healthy individuals. In addition, the combination panel, which include miR-134-5p, miR-15a-5p, and let-7i-5p scored better discriminatory power in differentiating STEMI patients from healthy controls. Procedural intervention for STEMI and NSTEMI are different. Hence, miRNAs that can discriminate between the two will aid in obtaining accurate intervention decision. Nevertheless, before these miRNAs can be used in clinical settings for diagnosis and/or therapeutic decision-making, evaluation in future trials with greater statistical power is warranted. CAD-associated miRNAs could be used to complement rather than to replace current diagnostic procedures to achieve rapid and greater accuracy in the stratification of ACS. In addition, elucidation is needed of the roles of these miRNAs in endothelial dysfunction, inflammation, cholesterol metabolism, and atherogenesis to provide clearer understandings to their contribution to the development and progression of ACS.

Author Contributions: K.-L.T., P.-F.W., and A.S.M.Z. participated in experimental design, data interpretation, and manuscript preparation. K.-L.T. performed experiments and A.S.M.Z. participated in patient recruitment and diagnosis. J.P.d.M. and P.-F.W. participated in small RNA sequencing data analysis. P.M.V., W.A.W.A., and M.R.M. are advisors to the project and provided critical review of the manuscript. All authors read and approved the final manuscript.

Acknowledgments: This study was supported by University of Malaya/Ministry of Higher Education (UM/MOHE) High Impact Research Grant (HIRG; account number, J-20001-73812). The authors are grateful to Jia-Shiun Khoo for her technical assistance on sRNA-seq analysis.

Conflicts of Interest: The authors have no competing interests associated with the manuscript.

\section{Abbreviations}

$\begin{array}{ll}\text { CAD } & \text { Coronary artery disease } \\ \text { ACS } & \text { Acute coronary syndrome } \\ \text { STEMI } & \text { ST-segment elevated myocardial infarction } \\ \text { NSTEMI } & \text { Non-ST-segment elevated myocardial infarction } \\ \text { ECG } & \text { Electrocardiography } \\ \text { CK-MB } & \text { Creatine kinase-myocardial band }\end{array}$




$\begin{array}{ll}\text { RT-PCR } & \text { Reverse transcription-polymerase chain reaction } \\ \text { HDL } & \text { High-density lipoproteins } \\ \text { sRNA-seq } & \text { Small RNA sequencing } \\ \text { FDR } & \text { False discovery rate } \\ \text { ANOVA } & \text { Analysis of variance } \\ \text { ROC } & \text { Receiver operating characteristic } \\ \text { AUC } & \text { Area under the curve } \\ \text { 95\% CI } & 95 \% \text { confidence interval } \\ \text { mESAdb } & \text { microRNA Expression and Sequence Analysis database } \\ \text { LDL } & \text { Low-density lipoproteins } \\ \text { VSMC } & \text { Vascular smooth muscle cells } \\ \text { SRs } & \text { Scavenger receptors } \\ \text { AGTR1 } & \text { Angiotensin II type 1 receptor } \\ \text { CVD } & \text { Cardiovascular disease } \\ \text { EDTA } & \text { Ethylenediaminetetraacetic acid } \\ \text { NRQ } & \text { Normalized relative quantity } \\ \text { RQ } & \text { Relative quantity } \\ \text { NF } & \text { Normalizing factor }\end{array}$

\section{References}

1. Cassar, A.; Holmes, D.R.; Rihal, C.S.; Gersh, B.J. Chronic Coronary Artery Disease: Diagnosis and Management. Mayo Clin. Proc. 2009, 84, 1130-1146. [CrossRef] [PubMed]

2. Morrow, D.A.; Cannon, C.P.; Jesse, R.L.; Newby, L.K.; Ravkilde, J.; Storrow, A.B.; Wu, A.H.; Christenson, R.H. National Academy of Clinical Biochemistry Laboratory Medicine Practice Guidelines: Clinical characteristics and utilization of biochemical markers in acute coronary syndromes. Circulation 2007, 115, e356-e375. [CrossRef] [PubMed]

3. Pollehn, T.; Brady, W.J.; Perron, A.D.; Morris, F. The electrocardiographic differential diagnosis of ST segment depression. Emerg. Med. J. 2002, 19, 129-135. [CrossRef] [PubMed]

4. Brady, W.J.; Roberts, D.; Morris, F. The nondiagnostic ECG in the chest pain patient: Normal and nonspecific initial ECG presentations of acute MI. Am. J. Emerg. Med. 1999, 17, 394-397. [CrossRef]

5. Venge, P.; James, S.; Jansson, L.; Lindahl, B. Clinical performance of two highly sensitive cardiac troponin I assays. Clin. Chem. 2009, 55, 109-116. [CrossRef] [PubMed]

6. Dekker, M.S.; Mosterd, A.; van Hof, A.W.; Hoes, A.W. Novel biochemical markers in suspected acute coronary syndrome: Systematic review and critical appraisal. Heart 2010, 96, 1001-1010. [CrossRef] [PubMed]

7. Tanindi, A.; Cemri, M. Troponin elevation in conditions other than acute coronary syndromes. Vasc. Health Risk Manag. 2011, 7, 597-603. [CrossRef] [PubMed]

8. Van Empel, V.P.; De Windt, L.J.; da Costa Martins, P.A. Circulating miRNAs: Reflecting or affecting cardiovascular disease? Curr. Hypertens. Rep. 2012, 14, 498-509. [CrossRef] [PubMed]

9. Wronska, A.; Kurkowska-Jastrzebska, I.; Santulli, G. Application of microRNAs in diagnosis and treatment of cardiovascular disease. Acta Physiol. 2015, 213, 60-83. [CrossRef] [PubMed]

10. Felekkis, K.; Touvana, E.; Stefanou, C.; Deltas, C. microRNAs: A newly described class of encoded molecules that play a role in health and disease. Hippokratia 2010, 14, 236-240. [PubMed]

11. Lee, R.C.; Feinbaum, R.L.; Ambros, V. Elegans heterochronic gene lin-4 encodes small RNAs with antisense complementarity to lin-14. Cell 1993, 75, 843-854. [CrossRef]

12. Wu, L.; Fan, J.; Belasco, J.G. MicroRNAs direct rapid deadenylation of mRNA. Proc. Natl. Acad. Sci. USA 2006, 103, 4034-4039. [CrossRef] [PubMed]

13. Ganci, F.; Sacconi, A.; Manciocco, V.; Covello, R.; Benevolo, M.; Rollo, F.; Strano, S.; Valsoni, S.; Bicciato, S.; Spriano, G.; et al. Altered peritumoral microRNA expression predicts head and neck cancer patients with a high risk of recurrence. Mod. Pathol. 2017, 30, 1387. [CrossRef] [PubMed]

14. Pennati, M.; Folini, M.; Gandellini, P.; Zaffaroni, N. MicroRNAs and the Response of Prostate Cancer to Anti-Cancer Drugs. Curr. Drug Targets 2016, 17, 257-265. [CrossRef] [PubMed] 
15. Andreou, I.; Sun, X.; Stone, P.H.; Edelman, E.R.; Feinberg, M.W. miRNAs in atherosclerotic plaque initiation, progression, and rupture. Trends Mol. Med. 2015, 21, 307-318. [CrossRef] [PubMed]

16. Bronze-da-Rocha, E. MicroRNAs expression profiles in cardiovascular diseases. BioMed Res. Int. 2014, 2014, 985408. [CrossRef] [PubMed]

17. Hoekstra, M.; van der Lans, C.A.; Halvorsen, B.; Gullestad, L.; Kuiper, J.; Aukrust, P.; van Berkel, T.J.; Biessen, E.A. The peripheral blood mononuclear cell microRNA signature of coronary artery disease. Biochem. Biophys. Res. Commun. 2010, 394, 792-797. [CrossRef] [PubMed]

18. Xiao, J.; Jing, Z.C.; Ellinor, P.T.; Liang, D.; Zhang, H.; Liu, Y.; Chen, X.; Pan, L.; Lyon, R.; Liu, Y.; et al. MicroRNA-134 as a potential plasma biomarker for the diagnosis of acute pulmonary embolism. J. Transl. Med. 2011, 9, 159. [CrossRef] [PubMed]

19. Oerlemans, M.I.; Mosterd, A.; Dekker, M.S.; de Vrey, E.A.; van Mil, A.; Pasterkamp, G.; Doevendans, P.A.; Hoes, A.W.; Sluijter, J.P. Early assessment of acute coronary syndromes in the emergency department: The potential diagnostic value of circulating microRNAs. EMBO Mol. Med. 2012, 4, 1176-1185. [CrossRef] [PubMed]

20. Wang, K.J.; Zhao, X.; Liu, Y.Z.; Zeng, Q.T.; Mao, X.B.; Li, S.N.; Zhang, M.; Jiang, C.; Zhou, Y.; Qian, C.; et al. Circulating MiR-19b-3p, MiR-134-5p and MiR-186-5p are Promising Novel Biomarkers for Early Diagnosis of Acute Myocardial Infarction. Cell. Physiol. Biochem. 2016, 38, 1015-1029. [CrossRef] [PubMed]

21. Dai, X.; Busby-Whitehead, J.; Alexander, K.P. Acute coronary syndrome in the older adults. J. Geriatr. Cardiol. JGC 2016, 13, 101-108. [CrossRef] [PubMed]

22. Gacon, J.; Kablak-Ziembicka, A.; Stepien, E.; Enguita, F.J.; Karch, I.; Derlaga, B.; Zmudka, K.; Przewlocki, T. Decision-making microRNAs (miR-124, -133a/b, -34a and -134) in patients with occluded target vessel in acute coronary syndrome. Kardiol. Polska 2016, 74, 280-288. [CrossRef] [PubMed]

23. Cantu-Brito, C.; Chiquete, E.; Ruiz-Sandoval, J.L.; Gaxiola, E.; Albuquerque, D.C.; Corbalan, R.; Ramos, A.; Bhatt, D.L.; Steg, P.G. Atherothrombotic disease, traditional risk factors, and 4-year mortality in a Latin American population: The REACH Registry. Clin. Cardiol. 2012, 35, 451-457. [CrossRef] [PubMed]

24. Previtali, E.; Bucciarelli, P.; Passamonti, S.M.; Martinelli, I. Risk factors for venous and arterial thrombosis. Blood Transfus. 2011, 9, 120-138. [PubMed]

25. Wan Azman, W.A.; Sim, K.H. Annual Report of the NCVD-ACS Registry, Year 2011-2013; National Heart Association of Malaysia (NHAM) and the Clinical Research Centre, Ministry of Health Malaysia: Kuala Lumpur, Malaysia, 2015.

26. Muda, Z.; Kadir, A.A.; Yusof, Z.; Yaacob, L.H. Premature Coronary Artery Disease among Angiographically Proven Atherosclerotic Coronary Artery Disease in North East of Peninsular Malaysia. Int. J. Collab. Res. Intern. Med. Public Health 2013, 5, 507-516.

27. Arantes, C.; Martins, J.; Braga, C.G.; Ramos, V.; Vieira, C.; Gaspar, A.; Salgado, A.; Pereira, M.A.; Rocha, S.; Correia, A. Acute coronary syndrome in young adults. Eur. Heart J. 2013, 34 (Suppl. 1), P3134. [CrossRef]

28. Teixeira, M.; Sa, I.; Mendes, J.S.; Martins, L. Acute coronary syndrome in young adults. Port. J. Cardiol. Off. J. Port. Soc. Cardiol. 2010, 29, 947-955.

29. Che, J.; Li, G.; Shao, Y.; Niu, H.; Shi, Y. An analysis of the risk factors for premature coronary artery disease in young and middle-age Chinese patients with hypertension. Exp. Clin. Cardiol. 2013, 18, 89-92. [PubMed]

30. Kang, S.M.; Choi, J.W.; Lee, Y.; Hong, S.H.; Lee, H.J. Identification of microRNA-size, small RNAs in Escherichia coli. Curr. Microbiol. 2013, 67, 609-613. [CrossRef] [PubMed]

31. Lagos-Quintana, M.; Rauhut, R.; Lendeckel, W.; Tuschl, T. Identification of novel genes coding for small expressed RNAs. Science 2001, 294, 853-858. [CrossRef] [PubMed]

32. Love, M.I.; Huber, W.; Anders, S. Moderated estimation of fold change and dispersion for RNA-seq data with DESeq2. Genome Biol. 2014, 15, 550. [CrossRef] [PubMed]

33. DeLong, E.R.; DeLong, D.M.; Clarke-Pearson, D.L. Comparing the areas under two or more correlated receiver operating characteristic curves: A nonparametric approach. Biometrics 1988, 44, 837-845. [CrossRef] [PubMed]

34. Kaya, K.D.; Karakulah, G.; Yakicier, C.M.; Acar, A.C.; Konu, O. mESAdb: MicroRNA expression and sequence analysis database. Nucleic Acids Res. 2011, 39, D170-D180. [CrossRef] [PubMed]

35. Chen, E.Y.; Tan, C.M.; Kou, Y.; Duan, Q.; Wang, Z.; Meirelles, G.V.; Clark, N.R.; Ma'ayan, A. Enrichr: Interactive and collaborative HTML5 gene list enrichment analysis tool. BMC Bioinform. 2013, 14, 128. [CrossRef] [PubMed] 
36. Kuleshov, M.V.; Jones, M.R.; Rouillard, A.D.; Fernandez, N.F.; Duan, Q.; Wang, Z.; Koplev, S.; Jenkins, S.L.; Jagodnik, K.M.; Lachmann, A.; et al. Enrichr: A comprehensive gene set enrichment analysis web server 2016 update. Nucleic Acids Res. 2016, 44, W90-W97. [CrossRef] [PubMed]

37. Economou, E.K.; Oikonomou, E.; Siasos, G.; Papageorgiou, N.; Tsalamandris, S.; Mourouzis, K.; Papaioanou, S.; Tousoulis, D. The role of microRNAs in coronary artery disease: From pathophysiology to diagnosis and treatment. Atherosclerosis 2015, 241, 624-633. [CrossRef] [PubMed]

38. Jones Buie, J.N.; Goodwin, A.J.; Cook, J.A.; Halushka, P.V.; Fan, H. The role of miRNAs in cardiovascular disease risk factors. Atherosclerosis 2016, 254, 271-281. [CrossRef] [PubMed]

39. Navickas, R.; Gal, D.; Laucevičius, A.; Taparauskaite, A.; Zdanytè, M.; Holvoet, P. Identifying circulating microRNAs as biomarkers of cardiovascular disease: A systematic review. Cardiovasc. Res. 2016, 111, 322-337. [CrossRef] [PubMed]

40. Widera, C.; Gupta, S.K.; Lorenzen, J.M.; Bang, C.; Bauersachs, J.; Bethmann, K.; Kempf, T.; Wollert, K.C.; Thum, T. Diagnostic and prognostic impact of six circulating microRNAs in acute coronary syndrome. J. Mol. Cell. Cardiol. 2011, 51, 872-875. [CrossRef] [PubMed]

41. Karakas, M.; Schulte, C.; Appelbaum, S.; Ojeda, F.; Lackner, K.J.; Munzel, T.; Schnabel, R.B.; Blankenberg, S.; Zeller, T. Circulating microRNAs strongly predict cardiovascular death in patients with coronary artery disease-results from the large AtheroGene study. Eur. Heart J. 2017, 38, 516-523. [CrossRef] [PubMed]

42. Adachi, T.; Nakanishi, M.; Otsuka, Y.; Nishimura, K.; Hirokawa, G.; Goto, Y.; Nonogi, H.; Iwai, N. Plasma microRNA 499 as a biomarker of acute myocardial infarction. Clin. Chem. 2010, 56, 1183-1185. [CrossRef] [PubMed]

43. Ai, J.; Zhang, R.; Li, Y.; Pu, J.; Lu, Y.; Jiao, J.; Li, K.; Yu, B.; Li, Z.; Wang, R.; et al. Circulating microRNA-1 as a potential novel biomarker for acute myocardial infarction. Biochem. Biophys. Res. Commun. 2010, 391, 73-77. [CrossRef] [PubMed]

44. Cheng, Y.; Tan, N.; Yang, J.; Liu, X.; Cao, X.; He, P.; Dong, X.; Qin, S.; Zhang, C. A translational study of circulating cell-free microRNA-1 in acute myocardial infarction. Clin. Sci. 2010, 119, 87-95. [CrossRef] [PubMed]

45. Corsten, M.F.; Dennert, R.; Jochems, S.; Kuznetsova, T.; Devaux, Y.; Hofstra, L.; Wagner, D.R.; Staessen, J.A.; Heymans, S.; Schroen, B. Circulating MicroRNA-208b and MicroRNA-499 reflect myocardial damage in cardiovascular disease. Circ. Cardiovasc. Genet. 2010, 3, 499-506. [CrossRef] [PubMed]

46. D'Alessandra, Y.; Devanna, P.; Limana, F.; Straino, S.; Di Carlo, A.; Brambilla, P.G.; Rubino, M.; Carena, M.C.; Spazzafumo, L.; De Simone, M.; et al. Circulating microRNAs are new and sensitive biomarkers of myocardial infarction. Eur. Heart J. 2010, 31, 2765-2773. [CrossRef] [PubMed]

47. Gidlof, O.; Andersson, P.; van der Pals, J.; Gotberg, M.; Erlinge, D. Cardiospecific microRNA plasma levels correlate with troponin and cardiac function in patients with ST elevation myocardial infarction, are selectively dependent on renal elimination, and can be detected in urine samples. Cardiology 2011, 118, 217-226. [CrossRef] [PubMed]

48. Ji, X.; Takahashi, R.; Hiura, Y.; Hirokawa, G.; Fukushima, Y.; Iwai, N. Plasma miR-208 as a biomarker of myocardial injury. Clin. Chem. 2009, 55, 1944-1949. [CrossRef] [PubMed]

49. Kuwabara, Y.; Ono, K.; Horie, T.; Nishi, H.; Nagao, K.; Kinoshita, M.; Watanabe, S.; Baba, O.; Kojima, Y.; Shizuta, S.; et al. Increased microRNA-1 and microRNA-133a levels in serum of patients with cardiovascular disease indicate myocardial damage. Circ. Cardiovasc. Genet. 2011, 4, 446-454. [CrossRef] [PubMed]

50. Olivieri, F.; Antonicelli, R.; Lorenzi, M.; D’Alessandra, Y.; Lazzarini, R.; Santini, G.; Spazzafumo, L.; Lisa, R.; La Sala, L.; Galeazzi, R.; et al. Diagnostic potential of circulating miR-499-5p in elderly patients with acute non ST-elevation myocardial infarction. Int. J. Cardiol. 2013, 167, 531-536. [CrossRef] [PubMed]

51. Wang, G.K.; Zhu, J.Q.; Zhang, J.T.; Li, Q.; Li, Y.; He, J.; Qin, Y.W.; Jing, Q. Circulating microRNA: A novel potential biomarker for early diagnosis of acute myocardial infarction in humans. Eur. Heart J. 2010, 31, 659-666. [CrossRef] [PubMed]

52. Fichtlscherer, S.; De Rosa, S.; Fox, H.; Schwietz, T.; Fischer, A.; Liebetrau, C.; Weber, M.; Hamm, C.W.; Roxe, T.; Muller-Ardogan, M.; et al. Circulating microRNAs in patients with coronary artery disease. Circ. Res. 2010, 107, 677-684. [CrossRef] [PubMed]

53. O'Sullivan, J.F.; Neylon, A.; McGorrian, C.; Blake, G.J. miRNA-93-5p and other miRNAs as predictors of coronary artery disease and STEMI. Int. J. Cardiol. 2016, 224, 310-316. [CrossRef] [PubMed] 
54. Satoh, M.; Minami, Y.; Takahashi, Y.; Tabuchi, T.; Nakamura, M. A cellular microRNA, let-7i, is a novel biomarker for clinical outcome in patients with dilated cardiomyopathy. J. Card. Fail. 2011, 17, 923-929. [CrossRef] [PubMed]

55. Lee, H.; Han, S.; Kwon, C.S.; Lee, D. Biogenesis and regulation of the let-7 miRNAs and their functional implications. Protein Cell 2016, 7, 100-113. [CrossRef] [PubMed]

56. Liao, Y.C.; Wang, Y.S.; Guo, Y.C.; Lin, W.L.; Chang, M.H.; Juo, S.H. Let-7g improves multiple endothelial functions through targeting transforming growth factor-beta and SIRT-1 signaling. J. Am. Coll. Cardiol. 2014, 63, 1685-1694. [CrossRef] [PubMed]

57. He, F.; Lv, P.; Zhao, X.; Wang, X.; Ma, X.; Meng, W.; Meng, X.; Dong, S. Predictive value of circulating miR-328 and miR-134 for acute myocardial infarction. Mol. Cell. Biochem. 2014, 394, 137-144. [CrossRef] [PubMed]

58. Lan, G.; Xie, W.; Li, L.; Zhang, M.; Liu, D.; Tan, Y.L.; Cheng, H.P.; Gong, D.; Huang, C.; Zheng, X.L.; et al. MicroRNA-134 actives lipoprotein lipase-mediated lipid accumulation and inflammatory response by targeting angiopoietin-like 4 in THP-1 macrophages. Biochem. Biophys. Res. Commun. 2016, 472, 410-417. [CrossRef] [PubMed]

59. Dai, Y.; Condorelli, G.; Mehta, J.L. Scavenger receptors and non-coding RNAs: Relevance in atherogenesis. Cardiovasc. Res. 2016, 109, 24-33. [CrossRef] [PubMed]

60. Gavard, J.; Gutkind, J.S. VE-cadherin and claudin-5: It takes two to tango. Nat. Cell Biol. 2008, 10, 883-885. [CrossRef] [PubMed]

61. Chang, C.W.; Wu, H.C.; Terry, M.B.; Santella, R.M. microRNA Expression in Prospectively Collected Blood as a Potential Biomarker of Breast Cancer Risk in the BCFR. Anticancer Res. 2015, 35, 3969-3977. [PubMed]

62. Tang, J.F.; Yu, Z.H.; Liu, T.; Lin, Z.Y.; Wang, Y.H.; Yang, L.W.; He, H.J.; Cao, J.; Huang, H.L.; Liu, G. Five miRNAs as novel diagnostic biomarker candidates for primary nasopharyngeal carcinoma. Asian Pac. J. Cancer Prev. APJCP 2014, 15, 7575-7581. [CrossRef] [PubMed]

63. Wojcicka, A.; Swierniak, M.; Kornasiewicz, O.; Gierlikowski, W.; Maciag, M.; Kolanowska, M.; Kotlarek, M.; Gornicka, B.; Koperski, L.; Niewinski, G.; et al. Next generation sequencing reveals microRNA isoforms in liver cirrhosis and hepatocellular carcinoma. Int. J. Biochem. Cell Biol. 2014, 53, 208-217. [CrossRef] [PubMed]

64. Cheng, Y.; Xiang, G.; Meng, Y.; Dong, R. MiRNA-183-5p promotes cell proliferation and inhibits apoptosis in human breast cancer by targeting the PDCD4. Reprod. Biol. 2016, 16, 225-233. [CrossRef] [PubMed]

65. Yang, S.; Krug, S.M.; Heitmann, J.; Hu, L.; Reinhold, A.K.; Sauer, S.; Bosten, J.; Sommer, C.; Fromm, M.; Brack, A.; et al. Analgesic drug delivery via recombinant tissue plasminogen activator and microRNA-183-triggered opening of the blood-nerve barrier. Biomaterials 2016, 82, 20-33. [CrossRef] [PubMed]

66. Morita, K.; Sasaki, H.; Furuse, M.; Tsukita, S. Endothelial Claudin: Claudin-5/Tmvcf Constitutes Tight Junction Strands in Endothelial Cells. J. Cell Biol. 1999, 147, 185-194. [CrossRef] [PubMed]

67. Wong, L.L.; Armugam, A.; Sepramaniam, S.; Karolina, D.S.; Lim, K.Y.; Lim, J.Y.; Chong, J.P.; Ng, J.Y.; Chen, Y.T.; Chan, M.M.; et al. Circulating microRNAs in heart failure with reduced and preserved left ventricular ejection fraction. Eur. J. Heart Fail. 2015, 17, 393-404. [CrossRef] [PubMed]

68. Chang, X.; Li, S.; Li, J.; Yin, L.; Zhou, T.; Zhang, C.; Chen, X.; Sun, K. Ethnic differences in microRNA-375 expression level and DNA methylation status in type 2 diabetes of Han and Kazak populations. J. Diabetes Res. 2014, 2014, 761938. [CrossRef] [PubMed]

69. Kelly, M.; Bagnall, R.D.; Peverill, R.E.; Donelan, L.; Corben, L.; Delatycki, M.B.; Semsarian, C. A polymorphic miR-155 binding site in AGTR1 is associated with cardiac hypertrophy in Friedreich ataxia. J. Mol. Cell. Cardiol. 2011, 51, 848-854. [CrossRef] [PubMed]

70. Sethupathy, P.; Borel, C.; Gagnebin, M.; Grant, G.R.; Deutsch, S.; Elton, T.S.; Hatzigeorgiou, A.G.; Antonarakis, S.E. Human microRNA-155 on chromosome 21 differentially interacts with its polymorphic target in the AGTR1 3' untranslated region: A mechanism for functional single-nucleotide polymorphisms related to phenotypes. Am. J. Hum. Genet. 2007, 81, 405-413. [CrossRef] [PubMed]

71. Pritchard, C.C.; Cheng, H.H.; Tewari, M. MicroRNA profiling: Approaches and considerations. Nat. Rev. Genet. 2012, 13, 358-369. [CrossRef] [PubMed]

72. Sun, H.X.; Zeng, D.Y.; Li, R.T.; Pang, R.P.; Yang, H.; Hu, Y.L.; Zhang, Q.; Jiang, Y.; Huang, L.Y.; Tang, Y.B.; et al. Essential role of microRNA-155 in regulating endothelium-dependent vasorelaxation by targeting endothelial nitric oxide synthase. Hypertension 2012, 60, 1407-1414. [CrossRef] [PubMed] 
73. Li, S.; Cao, C.; Chen, H.; Song, J.; Lee, C.; Zhang, J.; Zhang, F.; Geng, Q.; Li, Z.; Li, J. Atheroprotective effects of statins in patients with unstable angina by regulating the blood-borne microRNA network. Mol. Med. Rep. 2017, 16, 817-827. [CrossRef] [PubMed]

74. Ministry of Health. Clinical Practice Guidelines on Management of Unstable Angina/Non ST Elevation Myocardial Infarction (UA/NSTEMI); Ministry of Health: Putrajaya, Malaysia, 2011.

75. Ministry of Health Malaysia. Clinical Practice Guidelines-Management of Acute ST Segment Elevation Myocardial Infarction (STEMI), 3rd ed.; Ministry of Health Malaysia: Putrajaya, Malaysia, 2014.

76. Friedlander, M.R.; Mackowiak, S.D.; Li, N.; Chen, W.; Rajewsky, N. miRDeep2 accurately identifies known and hundreds of novel microRNA genes in seven animal clades. Nucleic Acids Res. 2012, 40, 37-52. [CrossRef] [PubMed]

77. Benjamini, Y.; Hochberg, Y. Controlling the False Discovery Rate: A Practical and Powerful Approach to Multiple Testing. J. R. Stat. Soc. Ser. B 1995, 57, 289-300.

78. Hellemans, J.; Mortier, G.; De Paepe, A.; Speleman, F.; Vandesompele, J. qBase relative quantification framework and software for management and automated analysis of real-time quantitative PCR data. Genome Biol. 2007, 8, R19. [CrossRef] [PubMed]

79. Vandesompele, J.; De Preter, K.; Pattyn, F.; Poppe, B.; Van Roy, N.; De Paepe, A.; Speleman, F. Accurate normalization of real-time quantitative RT-PCR data by geometric averaging of multiple internal control genes. Genome Biol. 2002, 3, RESEARCH0034. [CrossRef] [PubMed]

80. Baskerville, S.; Bartel, D.P. Microarray profiling of microRNAs reveals frequent coexpression with neighboring miRNAs and host genes. RNA 2005, 11, 241-247. [CrossRef] [PubMed]

81. Agarwal, V.; Bell, G.W.; Nam, J.W.; Bartel, D.P. Predicting effective microRNA target sites in mammalian mRNAs. eLife 2015, 4. [CrossRef] [PubMed]

82. Royston, P. A Remark on Algorithm AS 181: The W-test for Normality. J. R. Stat. Soc. Ser. C 1995, 44, $547-551$.

83. Shapiro, S.S.; Wilk, M.B. An analysis of variance test for normality (complete samples). Biometrika 1965, 52, 3-4. [CrossRef]

84. Sheskin, D.J. Handbook of Parametric and Nonparametric Statistical Procedures, 5th ed.; Chapman \& Hall/CRC 2000: Boca Raton, FL, USA, 2011.

85. Thode, H.J. Testing for Normality; Marcel Dekker: New York, NY, USA, 2002.

86. Liu, W.; Ling, S.; Sun, W.; Liu, T.; Li, Y.; Zhong, G.; Zhao, D.; Zhang, P.; Song, J.; Jin, X.; et al. Circulating microRNAs correlated with the level of coronary artery calcification in symptomatic patients. Sci. Rep. 2015, 5, 16099. [CrossRef] [PubMed]

87. Goren, Y.; Kushnir, M.; Zafrir, B.; Tabak, S.; Lewis, B.S.; Amir, O. Serum levels of microRNAs in patients with heart failure. Eur. J. Heart Fail. 2012, 14, 147-154. [CrossRef] [PubMed] 